\title{
7. INTERPRETATION OF MAGNETIC LOGS IN BASALT, HOLE 418A ${ }^{1}$
}

\author{
W. Bosum, Federal Institute for Geosciences and Natural Resources, Hannover ${ }^{2}$ \\ and \\ J. H. Scott, U.S. Geological Survey, Denver, Colorado ${ }^{3}$
}

\begin{abstract}
Borehole measurements of the Earth's magnetic field and the magnetic susceptibility of rocks penetrated by Hole 418A were made on Leg 102 with a gyroscope-oriented three-axis borehole magnetometer probe (Bundesanstalt für Geowissenschaften und Rohstoffe, Federal Republic of Germany) and a magnetic susceptibility probe (U.S. Geological Survey). Measurements made with the two probes were analyzed together to obtain the in-situ magnetic properties of pillow and massive basalts, which compared favorably with laboratory-measured equivalent properties of basement cores recovered from Hole 418A on DSDP Leg 53. The logs provide a continuous record of the magnetic characteristics of basalts penetrated by the borehole, which makes them useful for locating boundaries of lithologic units, for detecting polarity reversals, and for delineating zones with different magnetic inclinations. In addition, estimates of paleomagnetic pole positions interpreted from the Leg 102 borehole magnetic data compare favorably with Apparent Polar Wander Paths from shore-based paleomagnetic studies of oriented cores.
\end{abstract}

\section{INTRODUCTION}

The first borehole magnetic measurements of the Deep Sea Drilling Project were made on Legs 88,89 , and $78 \mathrm{~B}$ in Holes $501,504 \mathrm{~B}, 505 \mathrm{~B}$, and $395 \mathrm{~A}$ by a team of scientists from the U.S.S.R. using a three-component fluxgate magnetometer combined with a magnetic susceptibility meter (Ponomarev and Nechoroshkov, 1983, 1984). Although these logs represent a first in ocean drilling research, they cannot be analyzed for magnetic declination because the probe lacked a means of orientation independent of the magnetic measurements themselves. This shortcoming was overcome on Leg 102 by employing a gyroscope-oriented three-axis borehole magnetometer provided by the Bundesanstalt für Geowissenschaften und Rohstoffe, Federal Republic of Germany, and a magnetic susceptibility probe provided by the U.S. Geological Survey (USGS). Data from the two probes are complementary, and interpretations of in-situ magnetic properties of basalts compare favorably with laboratory measurements of cores from DSDP Leg 53.

The main objective of Leg 102 was to conduct comprehensive borehole geophysical measurements in old oceanic crust. Such measurements had been made successfully in young oceanic crust penetrated by Hole 504B, but there are none in old crust. Therefore, reentry was planned for one of the two deep basement Holes 417D and 418A to obtain equivalent information. Hole 418A was chosen for reentry on the basis of magnetic profiles made by the Glomar Challenger, from which the hole is believed to have been drilled near the eastern edge of the $M 0$ magnetic source that corresponds in age to the mid-Cretaceous. The basalts drilled at Hole 418A have been assigned an age of $110 \mathrm{Ma}$ based on isotopic and fission-track age dating, paleontological information, and magnetic-anomaly studies (Donnelly, Francheteau, et al., 1980). The location of Hole 418A is shown in Figure 1, and the location of the $M 0$ magnetic source in relation to Hole 418A is shown in Figure 2.

\footnotetext{
${ }^{1}$ Salisbury, M. H., Scott, J. H., et al., 1988. Proc. ODP, Sci. Results, 102: College Station, TX (Ocean Drilling Program).

2 Address: Federal Institute for Geosciences and Natural Resources, D-3000 Hannover 51, P.O. Box 5101 53, Federal Republic of Germany.

${ }^{3}$ Addresses: U.S. Geological Survey, M.S. 964, Box 25046, Denver Federal Center, Denver, CO 80225; (Present address) James H. Scott and Assoc., 12372 W. Louisiana Ave., Lakewood, CO 80228.
}

Laboratory measurements of magnetic properties were made of the core samples recovered when Hole $418 \mathrm{~A}$ was drilled in 1977 (Donnelly, Francheteau, et al., 1980). Therefore, the question to be considered is, What additional information can be gained from borehole magnetic measurements? In general, as pointed out in many papers and texts on well logging, it is advantageous to get information on petrographic properties more or less continuously and under in-situ conditions, whereas laboratory measurements can be made only on recovered cores, which often leaves gaps where rocks are weak or fractured. Furthermore, the process of removing the cores from their surroundings generally alters them to some degree, and in-situ conditions are not maintained. The advantages and disadvantages of both methods are considered in this paper by presenting the results of borehole magnetic measurements and comparing them with the laboratory studies reported by Levi et al. (1980), Bleil and Smith (1980), Levi (1980), Hamano et al. (1980), and Kelts and Giovanoli (1980).

The three-axis borehole magnetometer used on Leg 102 measures the magnetic field inside the borehole in three components, from which the direction and intensity of the total magnetization vector can be calculated. The susceptibility probe measures the magnetic susceptibility of rock to a depth of investigation of about $30 \mathrm{~cm}$. The direction and magnitude of induced magnetization can be determined from the susceptibility measurement and the known regional field. The combined data from the threeaxis magnetometer (total magnetization vector) and the magnetic susceptibility log (induced magnetization vector) can be used to compute the remanent magnetization of rocks around the borehole.

The susceptibility measurement is affected by both the concentration and the grain size of iron and iron titanium oxide minerals such as magnetite and titanomagnetite (Mooney and Bleifuss, 1953). Variations in susceptibility can be expected to correlate with variations in lithology and with the effects of alteration, which often destroys ferrimagnetic minerals such as magnetite or converts them to mineral species that have relatively low susceptibilities (e.g., pyrite, hematite). The direction and magnitude of remanent magnetization yield information on tectonic displacement and petrophysical properties such as grain size and concentration of magnetic minerals, and more importantly, when correlated with the geologic record of magnetic reversals and polar wandering, the remanent vector provides clues 


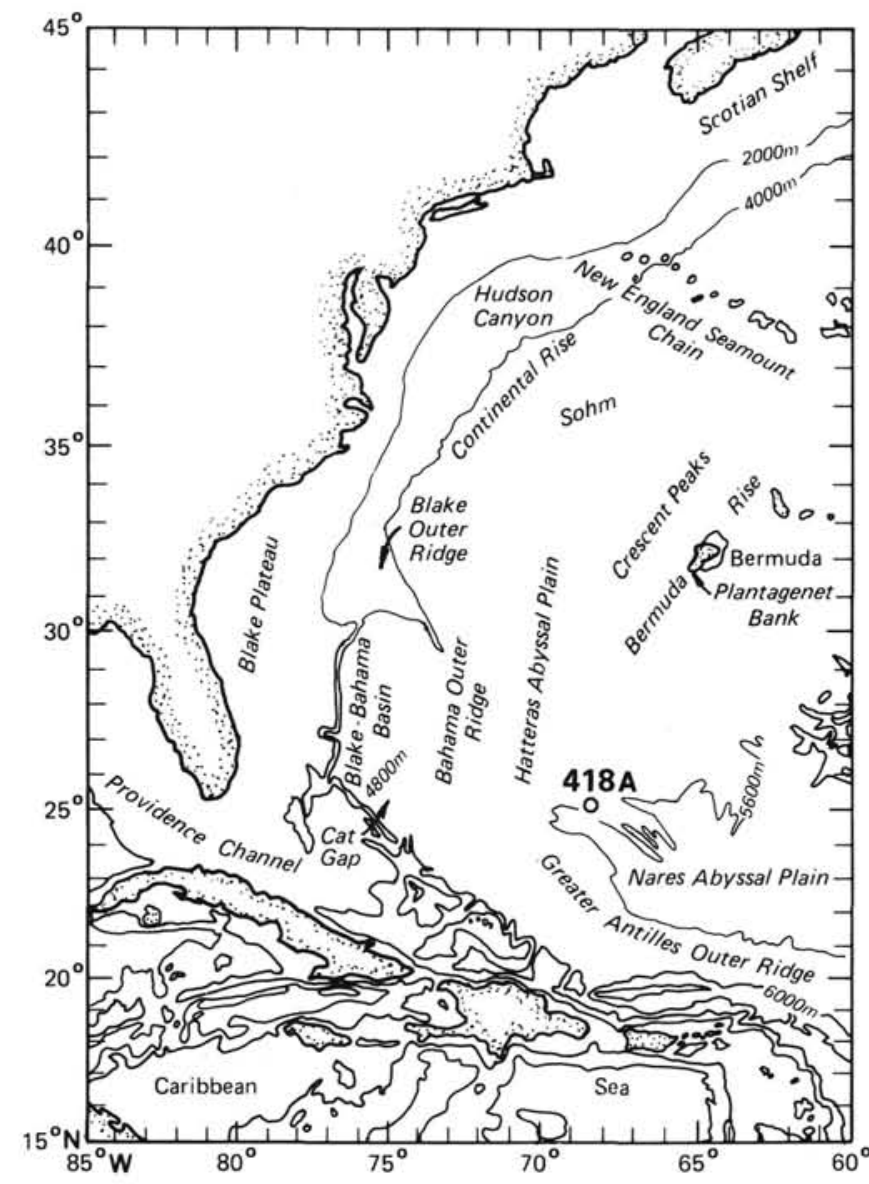

Figure 1. Location of Hole 418A.

regarding the age of rock formations or the age of metamorphic processes that transformed them. Therefore, when both susceptibility and magnetic field logs are available, they can shed light on the chemical and tectonic history of rocks, particularly if the rocks are crystalline and magmatic in origin and therefore have strong magnetic signatures. Oceanic basalts fall in this category.

\section{EQUIPMENT}

\section{The 3-D Magnetometer Probe}

Figure 3 shows the design of the 3-D magnetometer probe (Bosum et al., in press). The central measuring element is a three-axis Försterprobe fluxgate system with integrated electronics. The system measures the magnetic field in three mutually perpendicular directions, one parallel and two perpendicular to the axis of the borehole. A supplementary magnetic measurement is made with a gradiometer, which measures the gradient of the magnetic field parallel to the borehole by means of two additional fluxgates.

The probe also contains a directional reference unit consisting of a free gyroscope, which serves as a rotational reference for the probe, and two mutually perpendicular inclinometers (accelerometers), which measure the inclinations of the $\mathrm{x}$ - and $y$-axes of the three-axis magnetometer. The gyroscope itself is relatively large $(6.35-\mathrm{cm}$ diameter) and stable, rotating at 38,000 $\mathrm{rpm}$. The inclinometers measure the tilt of the probe in response to the effect of gravity on a mass-coil system.

The third important component of the probe is the electronics unit, consisting of signal-processing and data-transmission modules and a power supply. The electronics unit is connected by the logging cable to the surface unit, which consists of a computer with a peripheral plotter, an AC-to-DC converter, and a modem. The interconnection of these units and the flow of data between them is shown in Figure 4.

The computer controls the processes in the probe and the probe transmits the measurement information to the computer. Analog data from the triaxial fluxgate, gradiometer, and gyroscope-inclinometer directional unit are fed to the multiplexer, which connects one of the eight inputs to a 16-bit analog-to-digital converter on command from the computer. The digitized data are temporarily stored in a register, from which they are transmitted via the logging cable to the surface unit after being converted from parallel to serial format.

The probe housing is made of titanium, which is nonmagnetic and has a very high collapse strength. The system is designed to withstand a maximum temperature of about $70^{\circ} \mathrm{C}$ and a maximum pressure of $85 \mathrm{MPa}(12,300 \mathrm{psi})$.

The measurement accuracy of the various components has been determined experimentally as follows (Bosum and Eberle, 1982):

$\begin{array}{ll}\text { Försterprobe Fluxgate system } & \pm 1 \mathrm{nT} \\ \text { Gradiometer } & \pm 2 \mathrm{nT} / 40 \mathrm{~cm} \\ \text { Inclinometer } & \pm 5 \times 10^{-30} \\ \text { Gyroscope drift } & 0.5^{\circ} / \mathrm{hr} \text { (average) }\end{array}$

\section{The Susceptibility Probe}

The design and operating characteristics of the USGS prototype magnetic susceptibility tool have been described in detail by Scott et al. (1981). The probe used on Leg 102 was similar to the prototype, except for a few necessary changes to make it withstand the hydrostatic pressure at the bottom of Hole 418A, which was expected to approach $70 \mathrm{MPa}(10,000 \mathrm{psi})$. The probe contains a special-design solenoid sensing coil (Fig. 5) connected in a Maxwell induction bridge nulled in a zero-susceptibility environment (air) prior to logging. The solenoid in the Leg 102 probe is a three-layer coil with 1200 turns of $0.792-\mathrm{mm}$ coated copper wire wound on a ferrite core $1.5 \mathrm{~cm}$ in diameter and $30 \mathrm{~cm}$ long. The inductance of the coil is $174 \mathrm{mH}$, resistance is $4.5 \mathrm{ohms}$, and it has a Q of 240 . The coil is housed in the lower section of the probe, which is made of custom-designed laminar-glass epoxy tubing with an outside diameter of $7.0 \mathrm{~cm}$ and a wall thickness of $1.27 \mathrm{~cm}$. The tubing material survived a test of external fluid pressure held at $103 \mathrm{MPa}(15,000 \mathrm{psi})$ for one hour without leakage or physical distortion. The coil is in a heated chamber that maintains the temperature of the coil at $80^{\circ} \mathrm{C}$ by means of a proportional electronic regulator. The package containing the coil and heating units is filled with silicone grease with a relatively high thermal conductivity.

During logging, amplified samples of the off-null $1000-\mathrm{Hz}$ output signal from the Maxwell bridge and of the downhole $1000-\mathrm{Hz}$ bridge driving current are sent up the cable on separate lines. The surface control unit uses the bridge driving signal as a reference to separate the susceptibility component of the Maxwell bridge output signal from the resistivity component by phase discrimination. The output of the surface control unit includes three DC analog channels, representing the apparent magnetic susceptibility of rocks near the borehole, the apparent resistivity of the rocks, and the temperature of the coil in its heated chamber.

The $1000-\mathrm{Hz}$ measurement frequency is relatively low in comparison with the frequencies used to make conventional induction-logging resistivity measurements (typically $20-50 \mathrm{kHz}$ ) because measurement becomes more sensitive to susceptibility at lower frequencies. However, at $1000 \mathrm{~Hz}$ the measurement is relatively insensitive to variations in resistivity above $0.1 \mathrm{ohm}-\mathrm{m}$; 


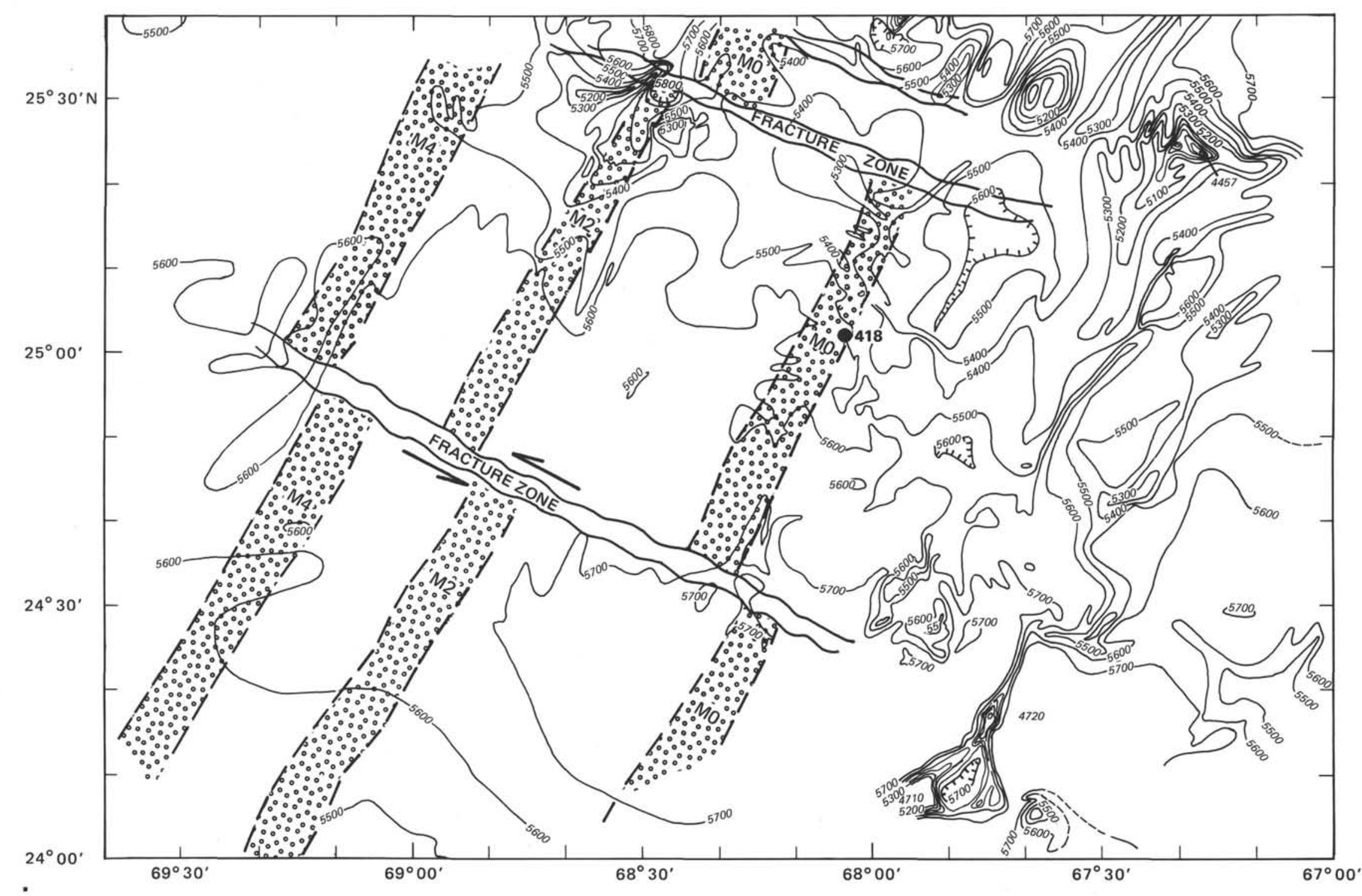

Figure 2. Bathymetry and position of magnetic source bodies near Site 418 (after Rabinowitz et al., 1980). 


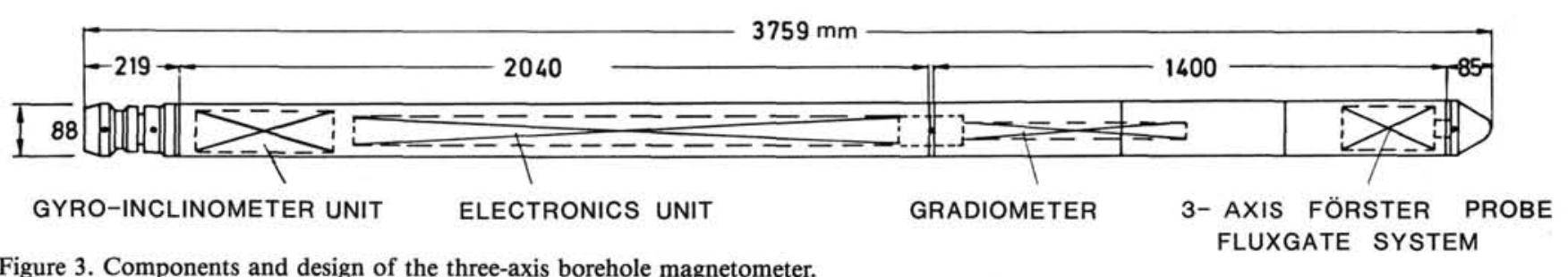

Figure 3. Components and design of the three-axis borehole magnetometer.

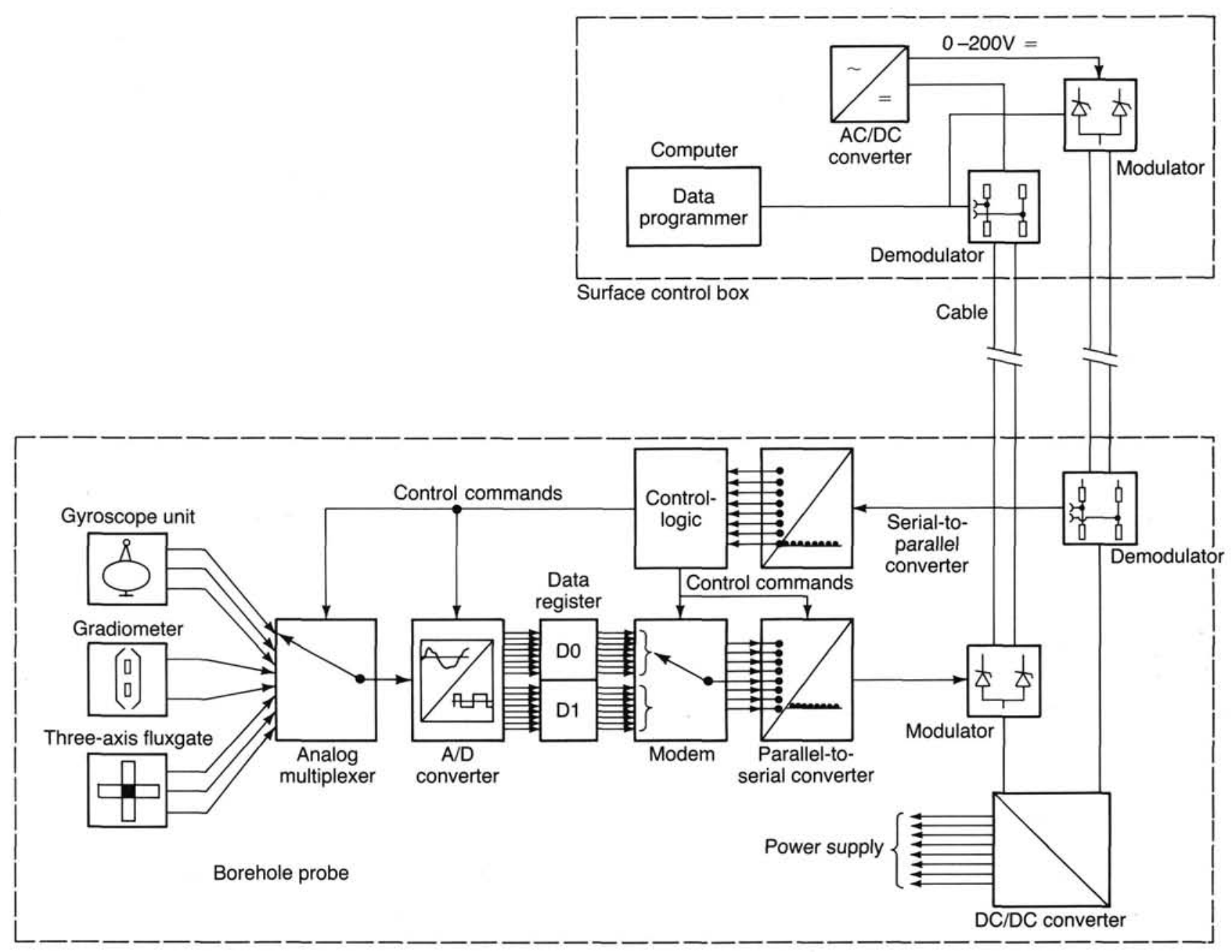

Figure 4. Block diagram of the three-axis borehole magnetometer system.

therefore, the resistivity channel of the susceptibility measurement system is generally useful only for sensing the presence of highly conductive minerals such as metallic sulfides and graphite.

All three output channels of the surface control unit are digitized and recorded on magnetic tape by a computer system for later playback and analysis. Figure 6 shows a block diagram of the surface and borehole electronic units and the flow of information between them.

\section{MEASUREMENT PROCEDURES}

\section{The 3-D Magnetometer Probe}

After the probe is connected to the logging cable, it is suspended vertically just above the drilling platform with the gyroscope caged (i.e., clamped so it cannot move in respect to the probe). The probe is oriented with a telescope temporarily attached to it by sighting on some distant fixed object aboard the ship. The heading of the ship is measured and recorded at this time for referencing the probe to an azimuthal direction. The gyroscope is uncaged (moving freely in respect to the probe), and the probe is lowered in the borehole to record downhole measurements. After completing the downhole measurements, the probe is raised to the drilling platform and reoriented by reattaching the telescope and sighting it on the same fixed object, again noting the ship's heading. These "before" and "after" readings are used to correct all of the intermediate downhole readings for gyroscope drift, which is assumed to be linear with time.

Downhole measurements are made in two modes: (1) in the magnetic logging mode, in which the probe moves either downward or upward continuously, and (2) in the 3-D measurements 


\section{AXIAL CROSS SECTION}
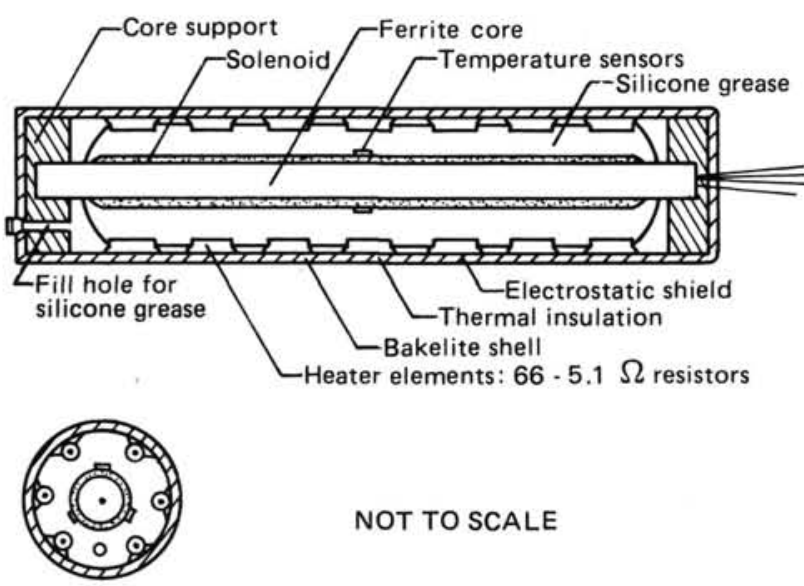

NOT TO SCALE

RADIAL

\section{CROSS SECTION}

Figure 5. Cross sections of magnetic susceptibility sensing coil, showing relative position of components.

mode, in which the probe is held stationary at discrete depth points. Any single parameter can be recorded in the magnetic logging mode, and the one that proved to be the most useful on Leg 102 was the vertical component of the Earth's magnetic field. The logging speed was about $275 \mathrm{~m} / \mathrm{hr}$ during magnetic logging, which yielded a spacing of about $8 \mathrm{~cm}$ between readings in the borehole.

In the 3-D measurement mode, all of the probe's magnetic and orientation measurement parameters were recorded at fixed depth increments of $5 \mathrm{~m}$. Ten consecutive readings were recorded at each station to improve the accuracy by selective averaging of the magnetic measurements and to provide an accurate value of probe orientation for the gyroscope drift correction. The following parameters were recorded at each station:

1. Azimuth of the $y$-axis of the three-axis fluxgate magnetometer referenced to the gyroscope.

2 . Inclination of the $x$ - and $y$-axes of the three-axis magnetometer referenced to the horizontal.

3. Differential magnetic field measured by the gradiometer.

4. Magnetic fields along the axes of the three-axis magnetometer.

From these measurements the X (east-west), Y (north-south), and $\mathrm{Z}$ (vertical) components of the Earth's magnetic field were calculated. As a byproduct, the inclination and the azimuth of inclination of the borehole were obtained from the gyroscopeinclinometer readings. The inclinometer measurements indicated that Hole $418 \mathrm{~A}$ deviated less than $2^{\circ}$ from vertical over the entire interval examined with the 3-D magnetometer probe, from 468 to $792 \mathrm{~m}$ below seafloor (mbsf).

\section{The Susceptibility Probe}

Just before the susceptibility probe is lowered into the borehole for a logging run, the probe is positioned in an anomalyfree environment with no conductive or magnetic objects within $1 \mathrm{~m}$ of the sensing coil. To null the output of the Maxwell bridge the bottom tip of the probe is removed to access two trimpots for adjustment based on the observed amplitudes of the susceptibility and resistivity analog output signals, which are displayed on two meters on the surface control panel. After the bridge is nulled, the tip of the probe is replaced, and the probe is lowered into the borehole to make the susceptibility log.

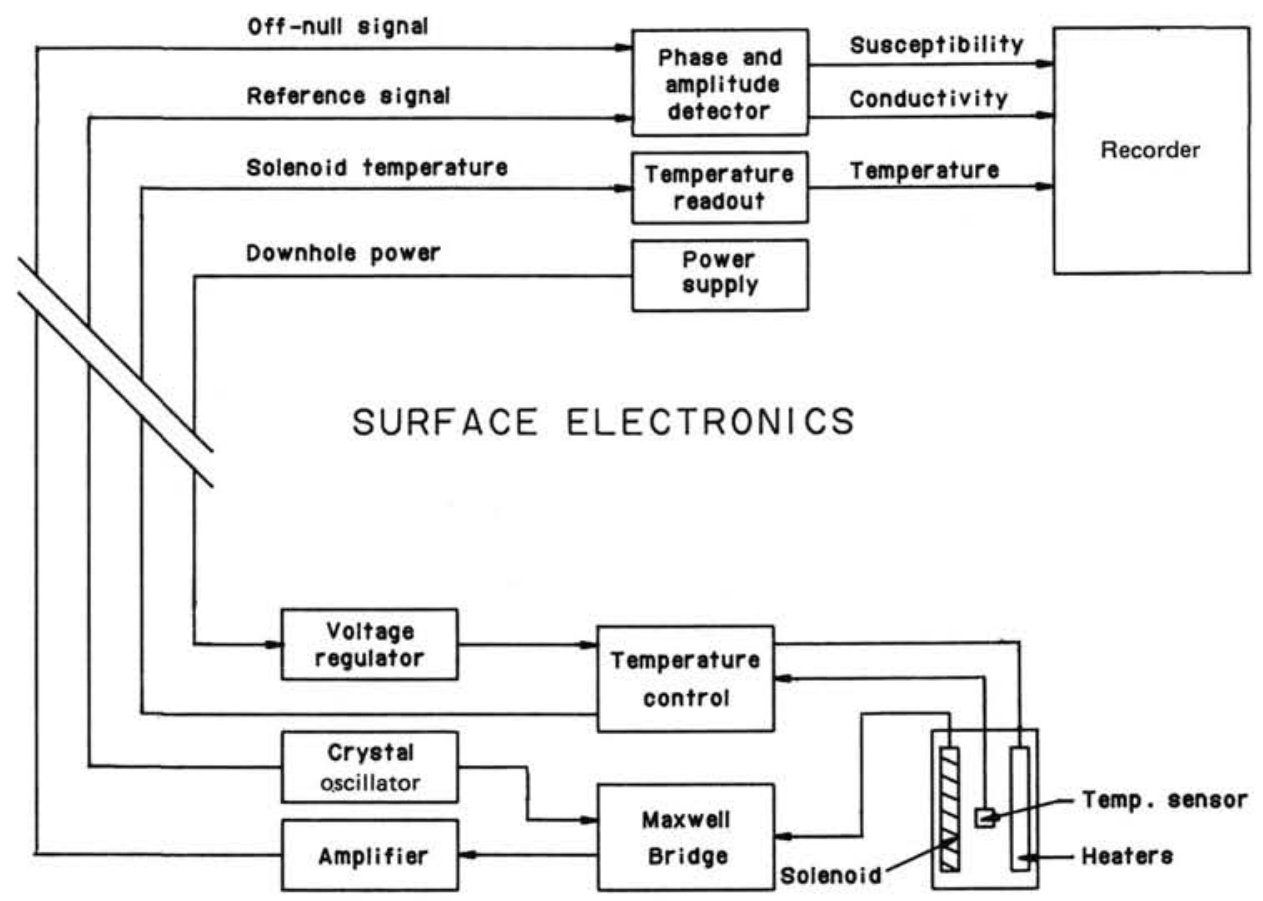

PROBE ELECTRONICS

Figure 6. Block diagram of probe electronics and surface electronics for the magnetic susceptibility welllogging system. 
When Hole 418A was logged, susceptibility readings were recorded on magnetic tape and an analog strip chart recorder as the probe was lowered and later raised through the open-hole sections. Because this was the first geophysical log run in Hole 418A during Leg 102, the susceptibility output was monitored carefully so that the winch could be stopped if the probe was prevented from moving downward because of a bridge or ledge in the borehole. This situation occurred several times. When stopped by an obstruction in the hole, the probe was raised and lowered several times in an attempt to break through. If this strategy failed, an upward-going log was recorded as the probe was raised toward the drill pipe. When the probe reached the pipe the withdrawal speed was increased to raise the probe as quickly as possible to the drilling platform, where it was removed from the pipe. The bridged interval in the hole was opened then by running the drill pipe deeper into the hole, leaving it positioned below the bridge. The probe was lowered back down the pipe again, and another downward run of the susceptibility log was made in the open hole below the pipe. Another upward logging run was made when the probe was stopped by the next obstruction, and as the probe approached the pipe, the pipe was raised by one length $(27 \mathrm{~m})$ so that the interval within and above the bridge was logged to produce an overlap in logging coverage. The next section of open hole was logged in a similar manner.

The Hole 418A susceptibility log was made in three such overlapping segments that were spliced together to form a continuous profile. Logging speed was approximately $500 \mathrm{~m} / \mathrm{hr}$ for the upward logging runs and $1500 \mathrm{~m} / \mathrm{hr}$ for the downward runs. Readings were recorded on magnetic tape at depth intervals of $0.2 \mathrm{~m}$ on the upward runs and $0.5 \mathrm{~m}$ on the downward runs. In general, the upward logging runs produced better logs than the downward runs because the cable remained taught, logging speed was steadier, and temperature regulation of the sensing coil was more effective, resulting in lower drift and a more stable log. The susceptibility log was digitized, recorded, and plotted by the shipboard Masscomp computer system using programs developed by Lamont-Doherty Geological Observatory (LDGO) personnel.

\section{DATA-REDUCTION METHODS}

\section{The Three-Axis Magnetometer Probe}

Before interpreting the borehole magnetic data, it is necessary to subtract the X (east-west), Y (north-south), and Z (vertical) components of the Earth's regional field in the vicinity of the borehole from the corresponding components calculated from the borehole magnetometer measurements of the field in the borehole. This reduces the anomalous components $\Delta \mathrm{X}, \Delta \mathrm{Y}$, and $\Delta \mathrm{Z}$.

Experience has shown that measuring the Earth's field in the vicinity of the borehole when the drillship is on site can be difficult or impossible because the field is disturbed by drill pipe, casing, and other strongly magnetic objects, including the ship itself. It is generally necessary to make supplemental total-field magnetic surveys in the site vicinity with a towed magnetometer for computing the $\mathrm{X}, \mathrm{Y}$, and $\mathrm{Z}$ components from regional inclination and declination maps. Unfortunately the JOIDES Resolution's towed magnetometer system was inoperable during Leg 102 , so we were unable to obtain total-field measurements. Therefore, we estimated the Earth's regional magnetic field from world maps based on International Geomagnetic Reference Field (IGRF) and marine magnetic surveys to obtain the following:

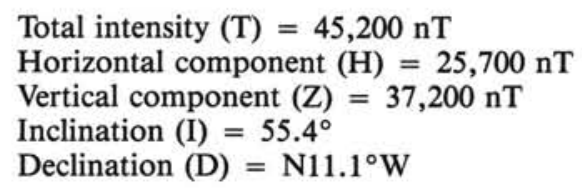

It should be noted that the magnetic anomalies are very strong in Hole 418A, and therefore, the uncertainty of regional magnetic field values, estimated to be $100-200 \mathrm{nT}$, did not significantly degrade results.

The log made with the probe in magnetic logging mode records the vertical component (Z) of the Earth's magnetic field. This log provides important information on the magnetic properties of the rock adjacent to the borehole and shows variations in magnetization and anomaly patterns that are diagnostic of rock type and direction of magnetization (normal or reversed). In order to display these variations more clearly and to provide quantitative magnetization values, the $\Delta \mathrm{Z}$ profile can be transformed to a magnetization profile. The magnetization profile is a conceptual disk model in which the rocks penetrated by the borehole are divided into thin horizontal slabs represented as disks of constant thickness and constant outer diameter with a hole of constant diameter cut through the center (Bosum, 1985).

The data from the probe operating in 3-D measurements mode can be analyzed to obtain the direction and intensity of magnetization of rock adjacent to the borehole at discrete depths. The relationship between the inclination of magnetization $I_{M}$ and the inclination of the anomalous field $\mathrm{I}_{\mathrm{F}}$ inside an extended body is given by

$$
\mathrm{I}_{\mathrm{M}}=\arctan \left(-1 / 2 \tan \mathrm{I}_{\mathrm{F}}\right),
$$

which follows from $\Delta \mathrm{Z}=-4 \pi \mathrm{M}_{\mathrm{Z}}$ and $\Delta \mathrm{H}=2 \pi \mathrm{M}_{\mathrm{H}}$, where $\mathrm{M}_{\mathrm{Z}}$ and $\mathrm{M}_{\mathrm{H}}$ are the vertical and horizontal magnetization components, with the declination of the magnetization and the anomalous field being equal (Bosum et al., in press).

\section{The Susceptibility Probe}

Reduction of the susceptibility data is relatively simple, involving the application of three types of corrections: (1) linear calibration corrections, (2) nonlinear (spline) drift corrections, and (3) nonlinear hole-diameter corrections (Scott, 1984). Calibration and hole-diameter corrections are based on empirical data obtained for the magnetic susceptibility probe at the USGS borehole test facility at the Denver Federal Center (Snodgrass, 1976). The hole-diameter correction for Hole 418A was made for an average diameter of 10.5 in., based on the Schlumberger caliper log data. Drift corrections were based on averages of core susceptibility measurements in low-susceptibility sections of the borehole.

\section{RESULTS AND INTERPRETATION}

\section{The Magnetometer Log}

The observed vertical-component magnetometer log is shown in Figure 7, and a smoothed version of the log together with a smoothed version of the susceptibility log are shown in Figure 8. Smoothing was done by computer with a 5-point Hamming filter. The normal value of the vertical component of the Earth's magnetic field is about $37,200 \mathrm{nT}$ at Site 418 , and this value is shown subtracted from the observed vertical intensity on the log scales at the base of the logs displayed in Figures 7 and 8 .

The most conspicuous feature of the magnetometer log is the change of sign (with respect to the normal field value) at a depth of about 504 mbsf. Only $10 \mathrm{~m}$ above this depth the residual vertical field is less than $-8000 \mathrm{nT}$, whereas $10 \mathrm{~m}$ below, it is more than $+7000 \mathrm{nT}$. This change is caused by a reversal of polarization of the lower basalt units, which is also indicated in laboratory measurements of core samples (Levi, 1980). The reversal coincides with a breccia zone at 504-514 mbsf on the lithology $\log$.

Below the breccia zone the magnetometer log can be divided into several different units based on the anomaly pattern and field strength. The strongest vertical fields and the smoothest 


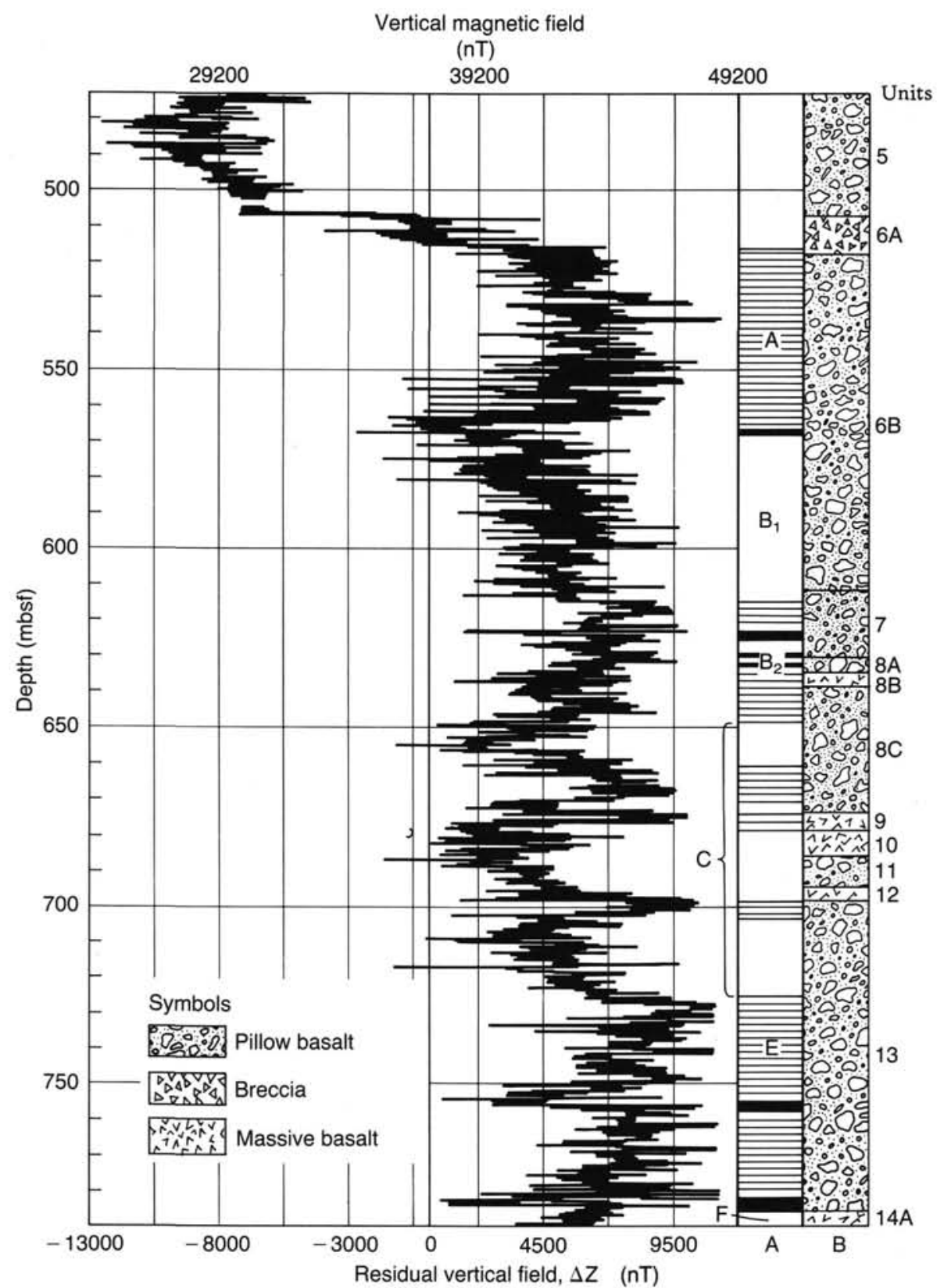

Figure 7. Shipboard magnetometer log from Hole 418A showing the vertical component of the Earth's magnetic field (normal value at Site $418=37,200 \mathrm{nT}$ ). A. Qualitative magnetic subdivisions based on the log. B. Lithologic column based on cores (after Donnelly, Francheteau, et al., 1980).

magnetic responses occur in sections A (514-565 mbsf), $\mathrm{B}_{1}(565-$ $610 \mathrm{mbsf})$, and E (725-785 mbsf), as shown in Figure 7, which indicates that these intervals are magnetically homogeneous.

Sections $B_{2}(610-645 \mathrm{mbsf})$ and $C$ (645-725 mbsf) are characterized by more heterogeneous behavior, in accord with the lithologic column, which shows frequent intercalation of massive basalt in sections of pillow basalt. The magnetic and petrographic boundaries often coincide approximately and probably would be in better agreement if it were not for a logging depth uncertainty of $\pm 2 \mathrm{~m}$ or more owing to cable stretch, ship's heave, and cable depth measurement inaccuracy. There is an even greater uncertainty in drilling depth introduced by incomplete core recovery and ship-positioning error. Discrete magnetic layers can be identified on the magnetometer log (Figs. 7 and 8) by comparison with the shape of a theoretical cylindrical source anomaly that represents a layer of negative vertical magnetization, as shown in Figure 9.

More details can be observed on plotting the magnetometer log on an expanded scale, an example of which is presented in Figure 10. Figure 10 also shows a comparison of downward and upward logging measurements (tracks $\mathrm{A}$ and $\mathrm{C}$ ), which indicates reasonably good repeatability. The main features are reproduced almost completely in repeat runs, and even the thin anomalies are in agreement in many cases. Differences between the downward and upward runs can be explained by the ship's heave and by variations in the distance between the probe and the borehole wall. Magnetic sources in the rock close to the borehole wall cause the magnetic field to vary horizontally as well as vertically 

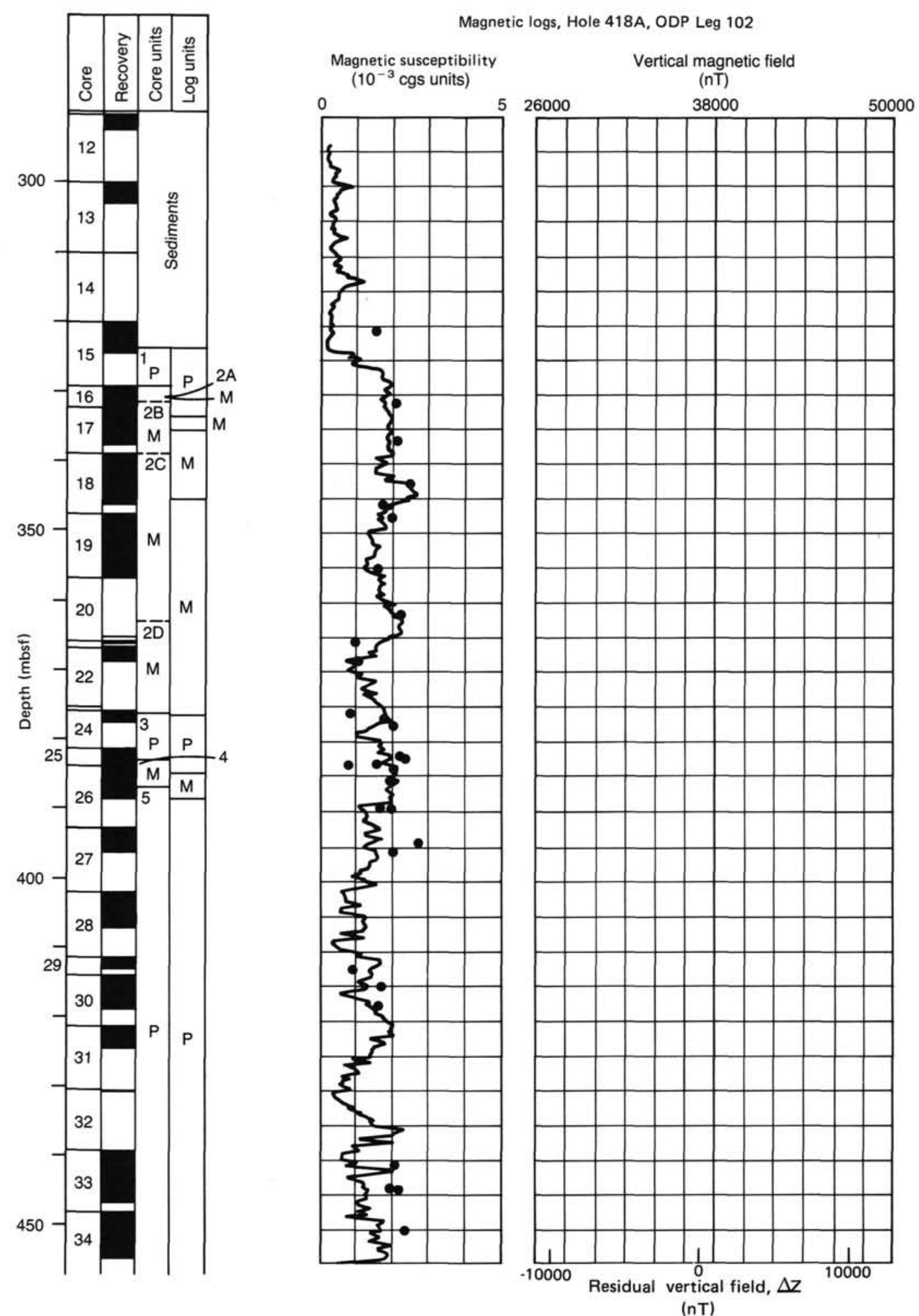

Figure 8. Lithologic and magnetic logging data from basement rocks and lower sediments, Hole 418A. Logging data smoothed with a 5-point Hamming filter with an effective length of $1 \mathrm{~m}$. Lithologic interpretation of core units after Donnelly, Francheteau, et al. (1980) and log units after Broglia and Moos (this volume) in track 1. Susceptibility log and lab data in track 2; vertical component magnetometer log in track 3.

in the borehole. The plotted azimuth of the probe's y-axis (tracks $\mathrm{B}$ and $\mathrm{D}$ ) indicates the probe's rotation as it was lowered and raised in the borehole.

Figures 11 and 12 are expanded-scale plots of the magnetometer $\log$ in other sections of the borehole. These figures illustrate the high degree of spatial resolution of the measurements and also the strong magnetic inhomogeneity of the rocks down to a depth of about 760 mbsf. Below this depth the magnetic field becomes smoother and declines as does the natural remanent magnetization (NRM) of the drill cores (Levi et al., 1980). 


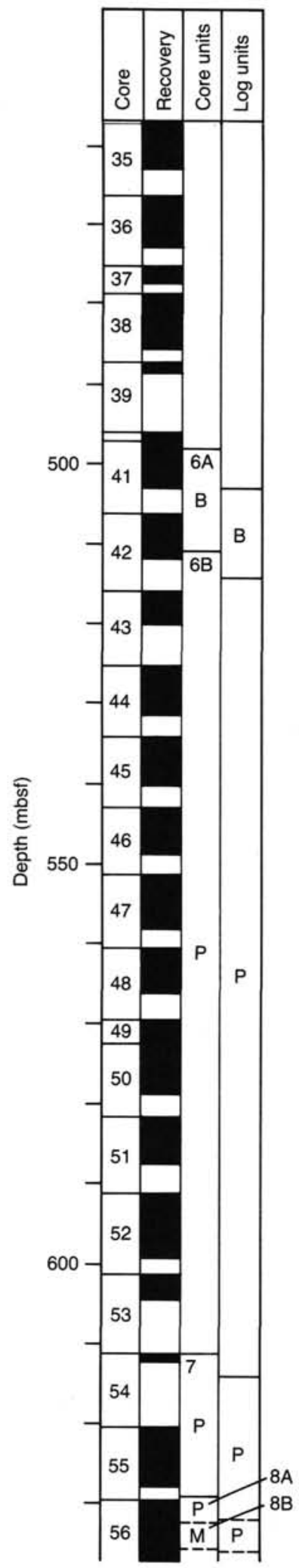

Figure 8 (continued).
Magnetic logs, Hole 418A, ODP Leg 102

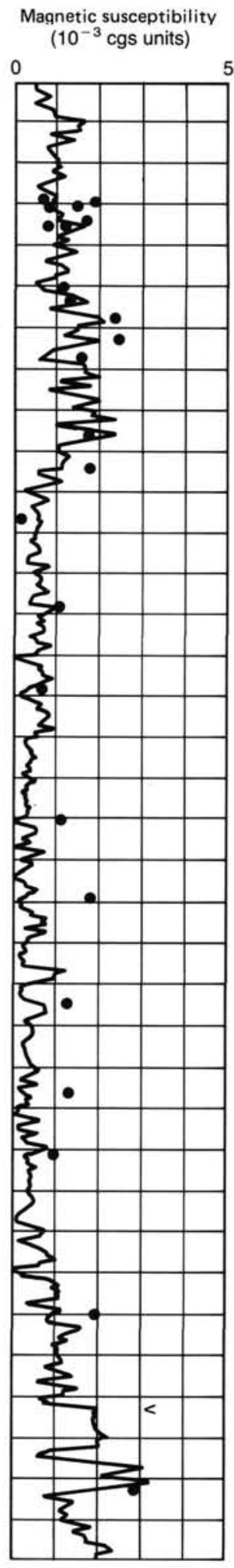
$\begin{array}{ccc} & & (\mathrm{nT}) \\ 5 & 26000 & 38000\end{array}$ 50000
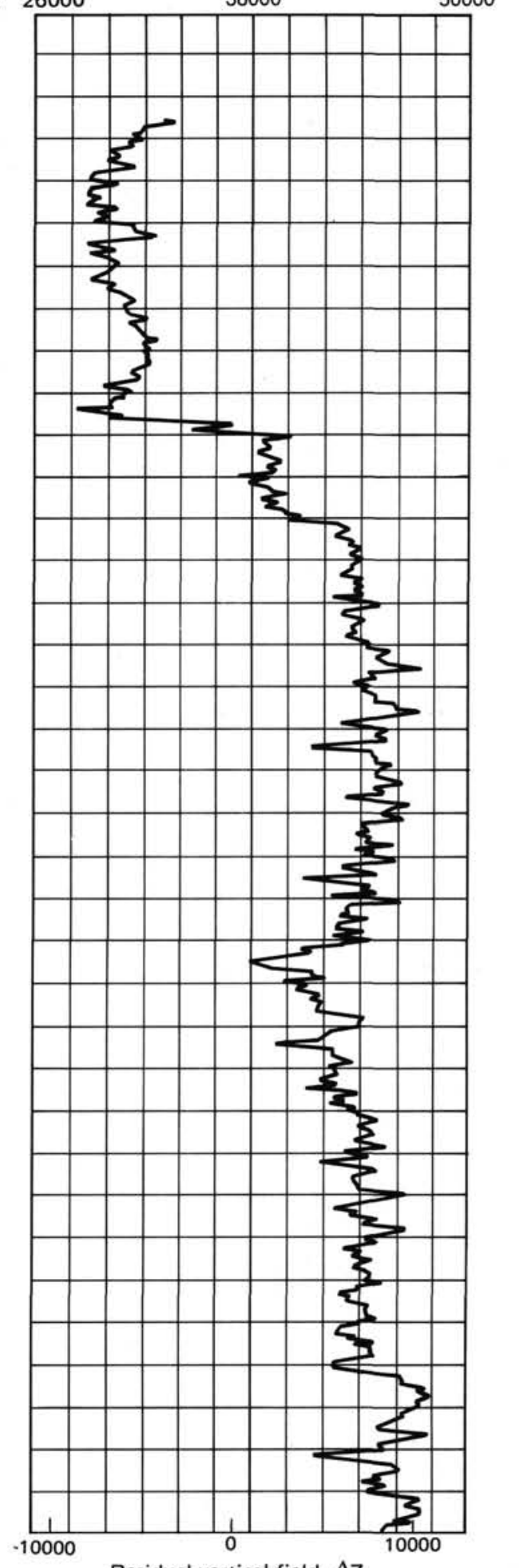

Residual vertical field, $\Delta \mathbf{z}$

(nT) 


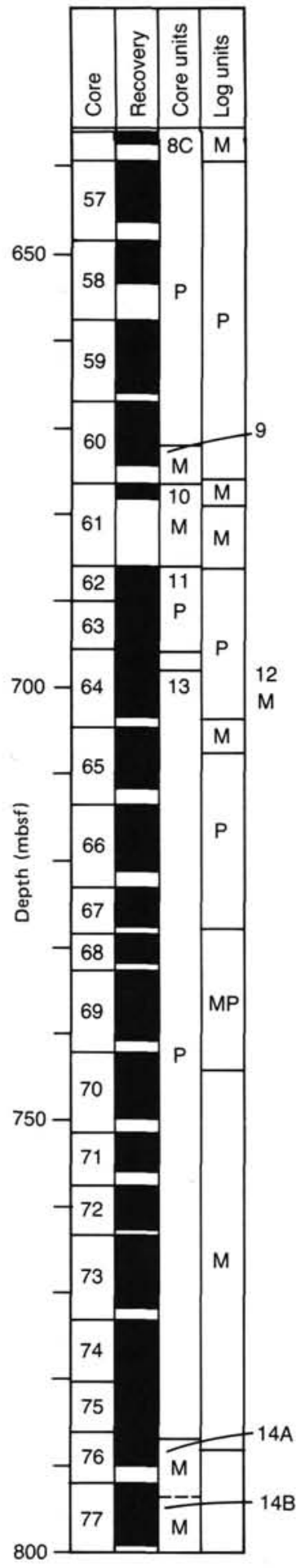

Magnetic logs, Hole 418A, ODP Leg 102
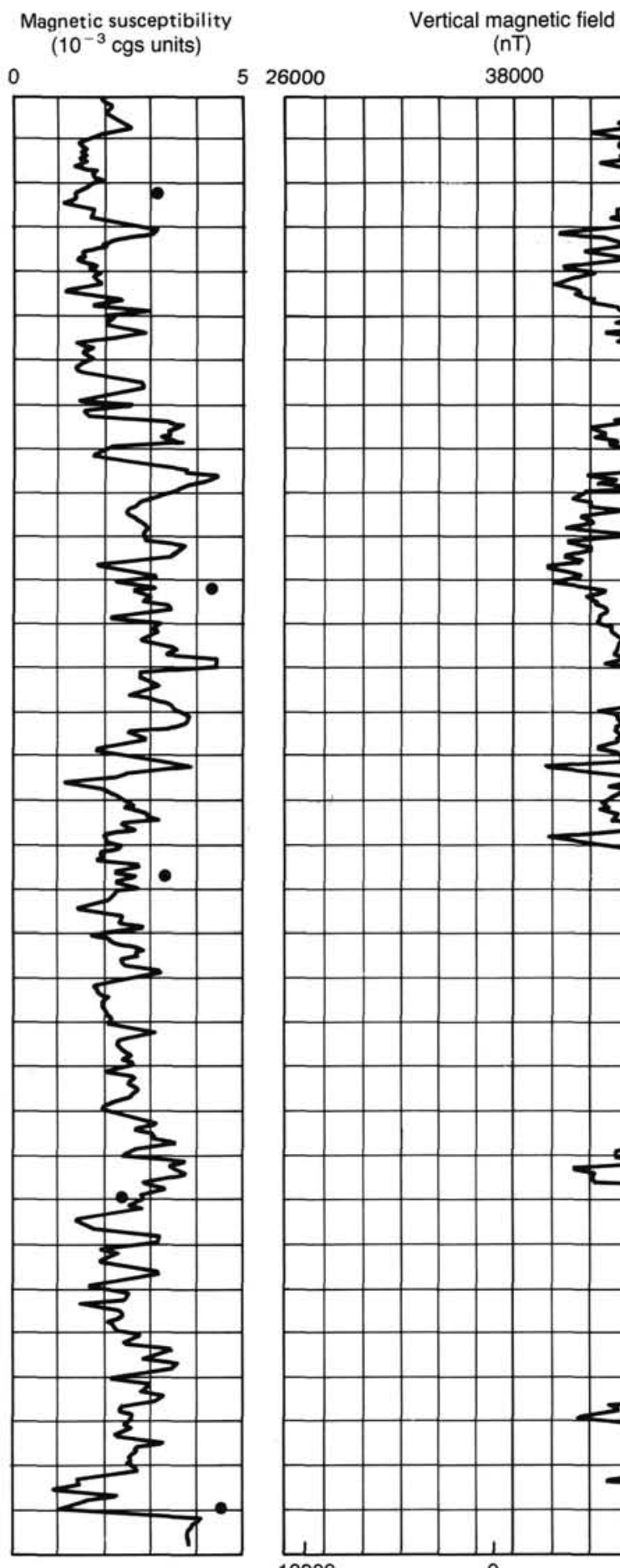

Vertical magnetic field
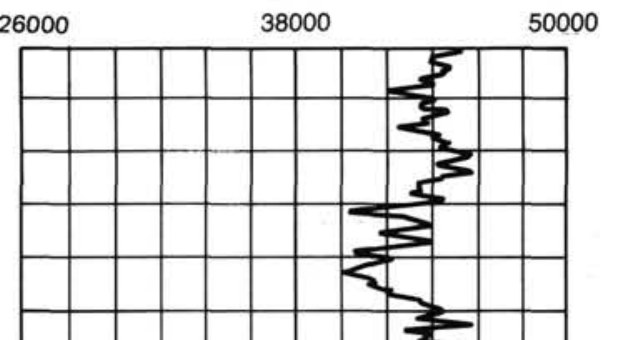

$P=$ Pillow basalt

$M=$ Massive basalt

$\mathrm{B}=$ Breccia

MP $=$ Massive pillow basalt

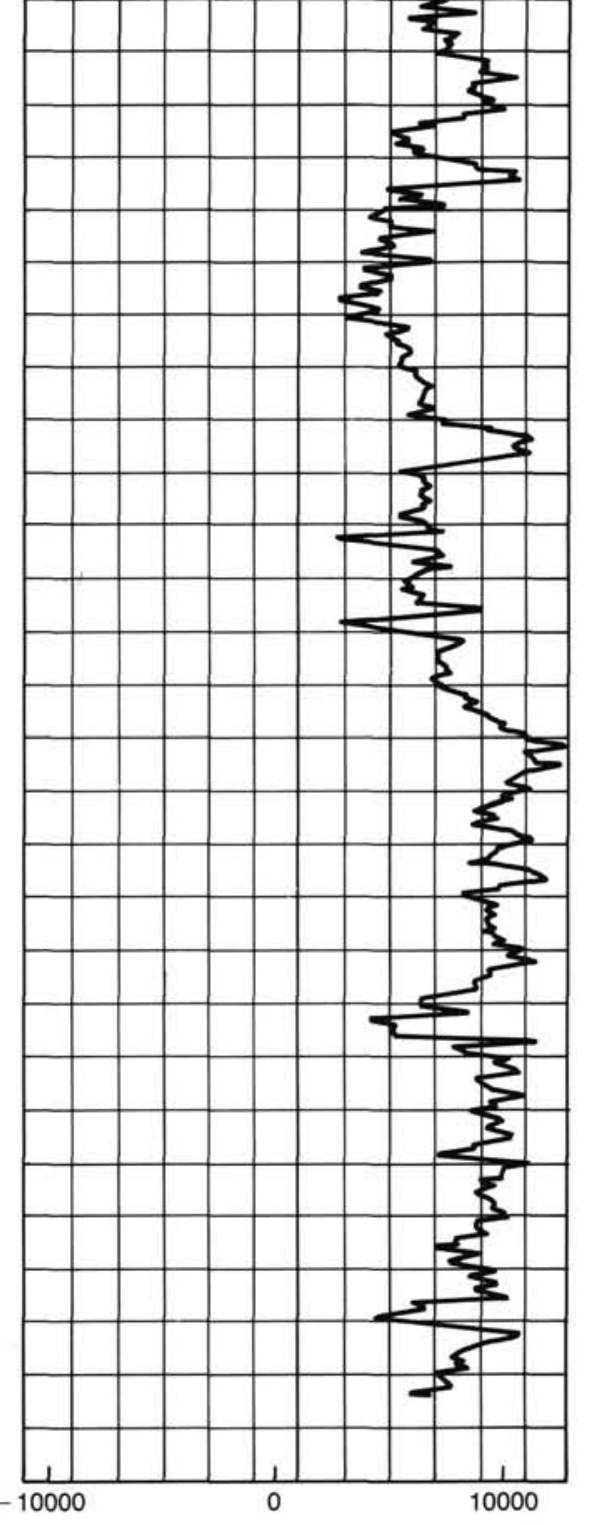

Residual vertical field, $\Delta Z$

(nT)

Figure 8 (continued). 


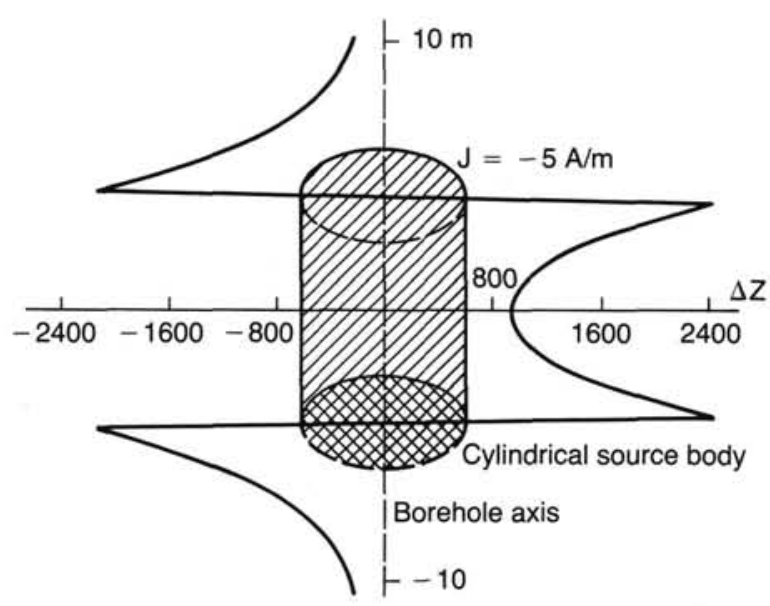

Figure 9. Theoretical vertical magnetic intensity anomaly along axis of borehole through a cylindrical source body.

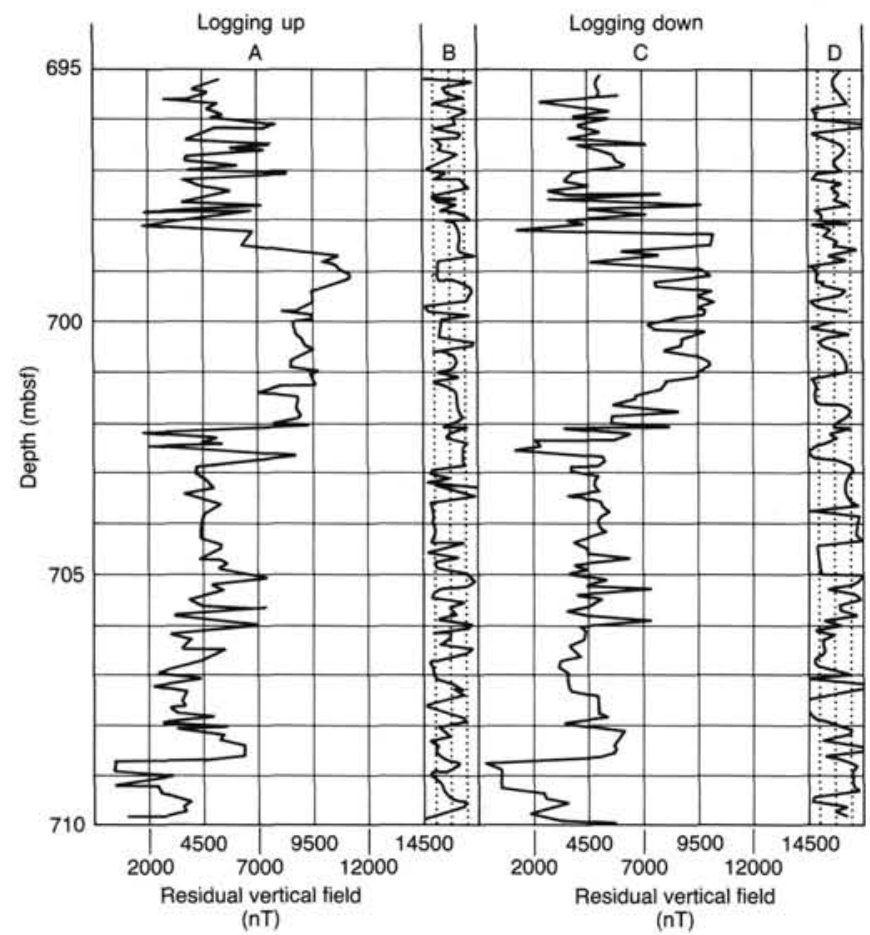

Figure 10. Shipboard plot of the vertical component magnetometer log of Hole 418A (A and C), and the azimuth of the probe's $y$-axis ( $\mathrm{B}$ and D) for the interval 695-710 mbsf. Upward logging (A and B); downward logging (C and $\mathrm{D})$.

The black layers in column $\mathrm{A}$ of Figure 7 indicate thin zones of low field levels caused by low absolute magnetizations. Because a thin zone $(3 \mathrm{~m})$ of reversely magnetized rocks is indicated by core measurements at a depth of about 625-628 mbsf (Levi et al., 1980) and because this reversal coincides with a minimum on the magnetometer log (also seen in Fig. 11), we wondered whether some or all of the other magnetic log minima represented reversals. We investigated this possibility by making some theoretical calculations for thin, normally polarized zones embedded in reversely polarized rocks.

Figure 13 shows the $\Delta \mathrm{Z}$ anomaly calculated for thin, normally magnetized layers of different thicknesses and different outer radii (with the magnetization $\mathrm{J}=10 \mathrm{~A} / \mathrm{m}$, in agreement

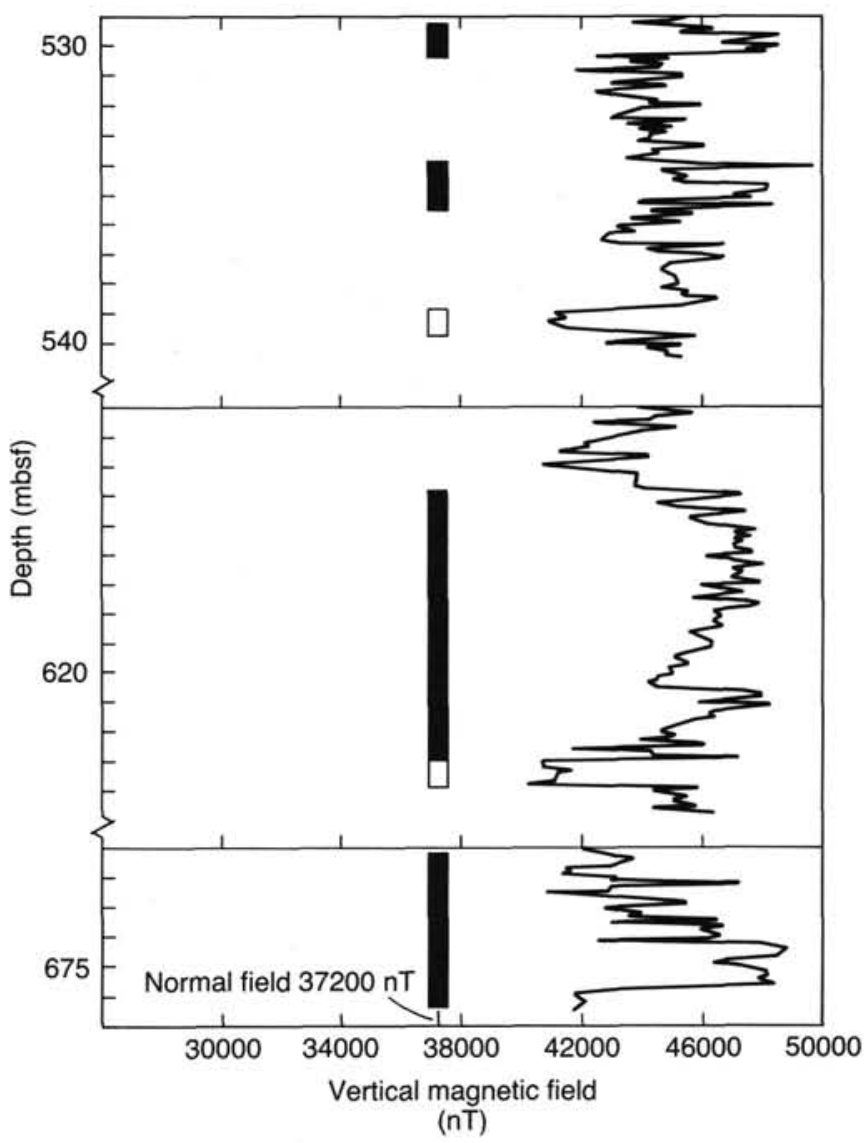

Figure 11. Expanded-scale plot of the magnetometer log from Hole 418A in three depth intervals, showing (mainly) positive magnetic anomalies resulting from local source bodies. Solid black bars represent sources with relatively low magnetizations that produce positive anomalies, and open bars represent sources with relatively high magnetizations.

with the laboratory results of Levi et al., 1980) embedded in reversely magnetized rocks. As indicated by these computed curves, strong negative anomalies are produced by normally polarized layers even if they are very thin. If the magnetization were less than $10 \mathrm{~A} / \mathrm{m}$, the embedded layer would still yield values less than zero. Because consistent negative values (above the noise level) are not observed on the magnetometer log except in and above the breccia zone, we conclude that the deeper low-intensity anomalies on the magnetometer log do not represent reversals.

The total magnetization profile was computed from the magnetometer log by the tabular disk model described earlier. The outer radius of the magnetic disks was determined by trial and error to be about $100 \mathrm{~m}$. Results are shown in Figure 14, with model computations at $0.6-\mathrm{m}$ depth intervals shown in the middle (B) and average values for thicker depth intervals of similar magnetic intensity shown in on the right (C). The observed log is on the left (A) for reference. The calculations yielded relatively high magnetizations of about $10 \mathrm{~A} / \mathrm{m}$ on the average. In general, the upper half of the log is characterized by higher magnetizations than the lower half. The NRM of the core magnetic measurements are plotted on the middle (B) as dots (Levi, 1980) and bars (Levi et al., 1980) for comparison. Because of the high Königsberger (Q) factor, which is the ratio of remanent to induced magnetization, the core NRM values correspond to the total magnetization computed from the magnetometer log. The laboratory values are even more scattered than the log-derived values because of the small sample volume of core and the mag- 


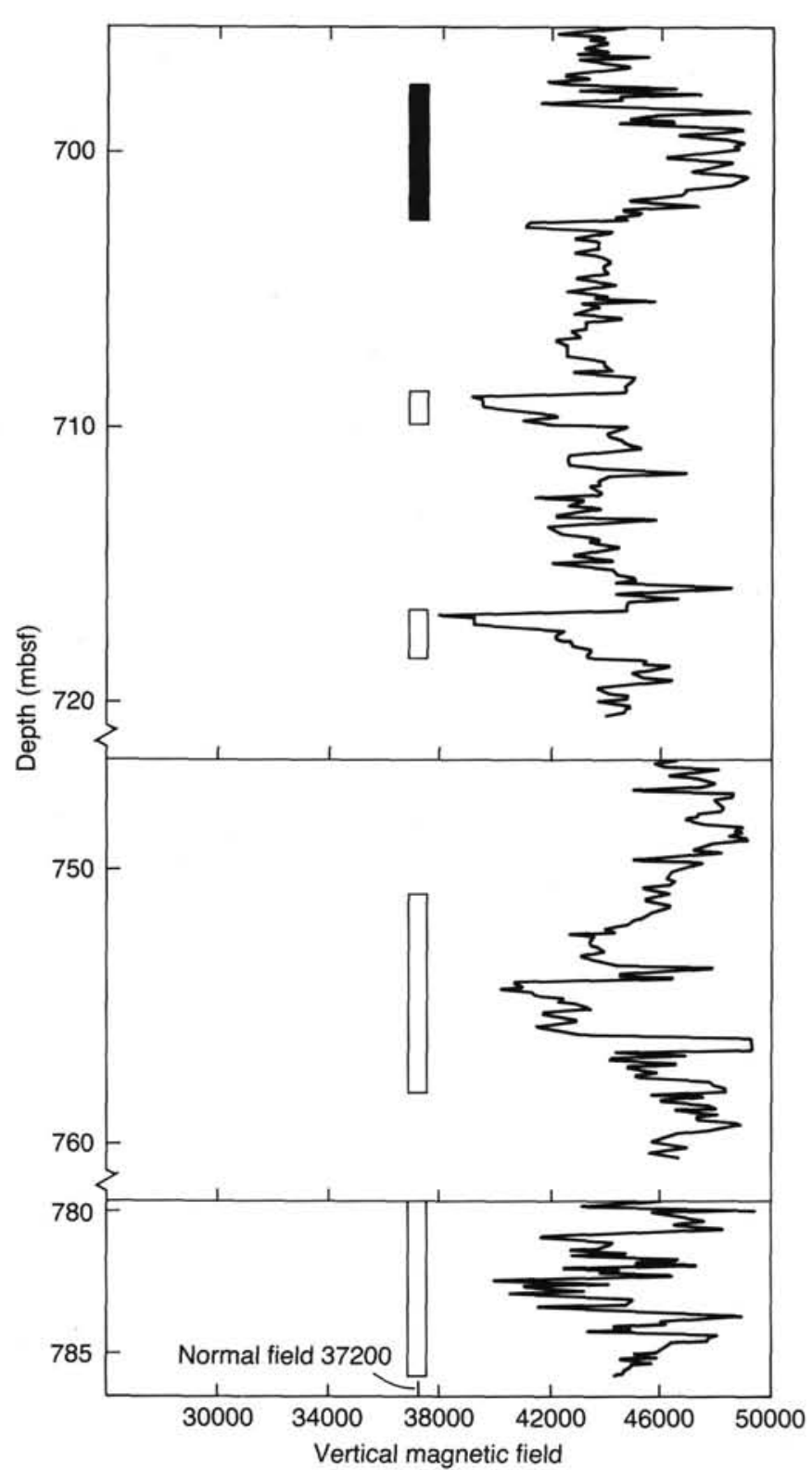

(nT)

Figure 12. Expanded-scale plot of the magnetometer log from Hole 418A for three depth intervals, showing (mainly) negative anomalies resulting from local source bodies. Open bars represent sources with relatively high magnetizations that produce negative anomalies, and solid black bars represent sources with low magnetizations.

netic heterogeneity of the rock. However, the two data sets track each other in a relative sense, although the core NRM values appear to be somewhat higher in absolute value than the log-derived values in the upper part of the logged interval whereas the opposite is true in the lower part. This suggests that the outer radius of the disk model should be less than $100 \mathrm{~m}$ in the upper part of the interval and greater than $100 \mathrm{~m}$ in the lower part, which may indicate that the $M 0$ source body (Larson and Hilde, 1975; Rabinowitz et al., 1980) is tilted with respect to Hole 418A (as we discuss subsequently).

\section{The Susceptibility Log}

The magnetic-susceptibility $\log$ is shown in Figure 8 along with the magnetometer log, lithology, and core recovery. The solid black circles show the laboratory susceptibility measurements of cores from Hole $418 \mathrm{~A}$ reported by Hamano et al (1980). The laboratory and borehole measurements agree reasonably well on the average, considering that there are significant differences in the volumes sampled by the two measurements and that the distribution of ferrimagnetic minerals is quite erratic, judging from the high degree of variability of the core measurements, the susceptibility log, and the magnetometer log.

As would be expected, susceptibility is quite low in the sedimentary section of the upper part of the hole, ranging from nearly zero to $1 \times 10^{-3} \mathrm{cgs}$ and averaging $0.3 \times 10^{-3} \mathrm{cgs}$ units.

Below the sediments, the predominantly massive basalts from 324 to 388 mbsf have a much higher susceptibility, ranging from about $1 \times 10^{-3}$ to $2.5 \times 10^{-3} \mathrm{cgs}$, with an average value close to $2 \times 10^{-3} \mathrm{cgs}$ units. This zone corresponds to lithologic Units $1-4$, which are characterized by low alteration, low smectite content, high sonic-wave velocities $\left(\mathrm{V}_{p}\right)$ of $>5 \mathrm{~km} / \mathrm{s}$, and low porosities of $<15 \%$ (Broglia and Moos, this volume).

The next zone (388-514 mbsf) corresponds to lithologic Unit 5 and Subunit $6 \mathrm{~A}$ and consists of altered pillow basalts with relatively high smectite content, low $\mathrm{V}_{p}$ ranging from 3.5 to $5.0 \mathrm{~km} / \mathrm{s}$, and relatively high porosity of $15 \%-25 \%$ (Broglia and Moos, this volume). The susceptibility log shows two natural subdivisions of this zone, the upper one (388-455 mbsf) composed of thicker beds with somewhat higher susceptibilities of about $2 \times 10^{-3} \mathrm{cgs}$, and the lower one (455-504 mbsf) containing thinner beds with more variable susceptibilities ranging from about $0.5 \times 10^{-3}$ to $2 \times 10^{-3} \mathrm{cgs}$. This zone is underlain by lithologic Subunit 6A (504-514 mbsf), a breccia zone, below which the direction of polarization changes from normal to reversed. The breccia itself has a low and uniform susceptibility of about $0.5 \times 10^{-3} \mathrm{cgs}$.

Below the breccia zone the susceptibility remains low in the interval 514-610 mbsf, ranging from 0 to $1 \times 10^{-3} \mathrm{cgs}$ and averaging about $0.4 \times 10^{-3} \mathrm{cgs}$ units, almost as low as that of the sedimentary section. This interval corresponds to sections A and $B_{1}$ of the magnetometer log and to lithologic Subunit 6B in the upper part of the zone of relatively fresh pillow basalts described by Broglia and Moos (this volume) as having low smectite content $(<5 \%)$, high $\mathrm{V}_{p}(4-6 \mathrm{~km} / \mathrm{s})$, and relatively low porosity $(<20 \%)$.

Below this interval, susceptibility increases and becomes highly variable in the interval $610-645$ mbsf, ranging from $0.6 \times$ $10^{-3}$ to $3.3 \times 10^{-3} \mathrm{cgs}$ and averaging nearly $2 \times 10^{-3} \mathrm{cgs}$ units. This interval corresponds to section $\mathrm{B}_{2}$ of the magnetometer log and to lithologic Unit 7 and Subunits $8 \mathrm{~A}$ and $8 \mathrm{~B}$, and its variability is probably due to the intercalation of massive basalts in the pillow basalts that dominate the interval.

From 645 to 725 mbsf, the susceptibility log reaches its highest levels, approaching $4.5 \times 10^{-3} \mathrm{cgs}$ and averaging nearly $3 \times$ $10^{-3} \mathrm{cgs}$ units. This interval corresponds to magnetometer log section $C$ and to lithologic Subunit $8 C$, Units 9 through 12, and the upper part of Unit 13. The magnetometer log as well as the susceptibility log show a high degree of variability in this interval because of the continuing intercalation of massive basalts in the pillows.

The interval from 725-785 mbsf (magnetometer log section E) is characterized by lower and more uniform susceptibilities ranging from about $1.4 \times 10^{-3}$ to $3.7 \times 10^{-3} \mathrm{cgs}$ and averaging about $2.5 \times 10^{-3} \mathrm{cgs}$ units. This interval contains relatively homogeneous massive pillow basalts and massive basalts (lithologic Subunits 13A-13C), which accounts for the relatively smooth susceptibility log response.

Just below 785 mbsf the susceptibility decreases to about $1 \times 10^{-3}$ cgs units in magnetometer $\log$ section $\mathrm{F}$, which corresponds to the massive basalt (lithologic Subunit 14A) just above the dike zone. The bottom of the susceptibility log barely pene- 


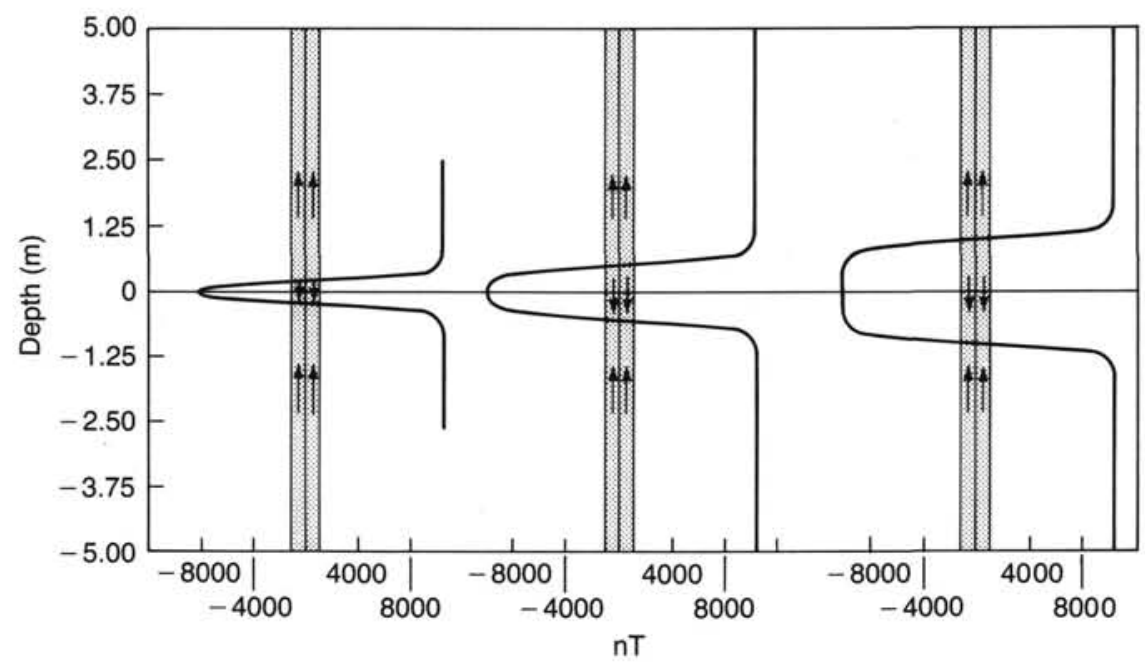

Figure 13. Computed borehole anomalies showing the effects of normally polarized layers of three different thicknesses embedded in reversely polarized host rock. Arrows indicate the direction of magnetization $( \pm 10 \mathrm{~A} / \mathrm{m})$.

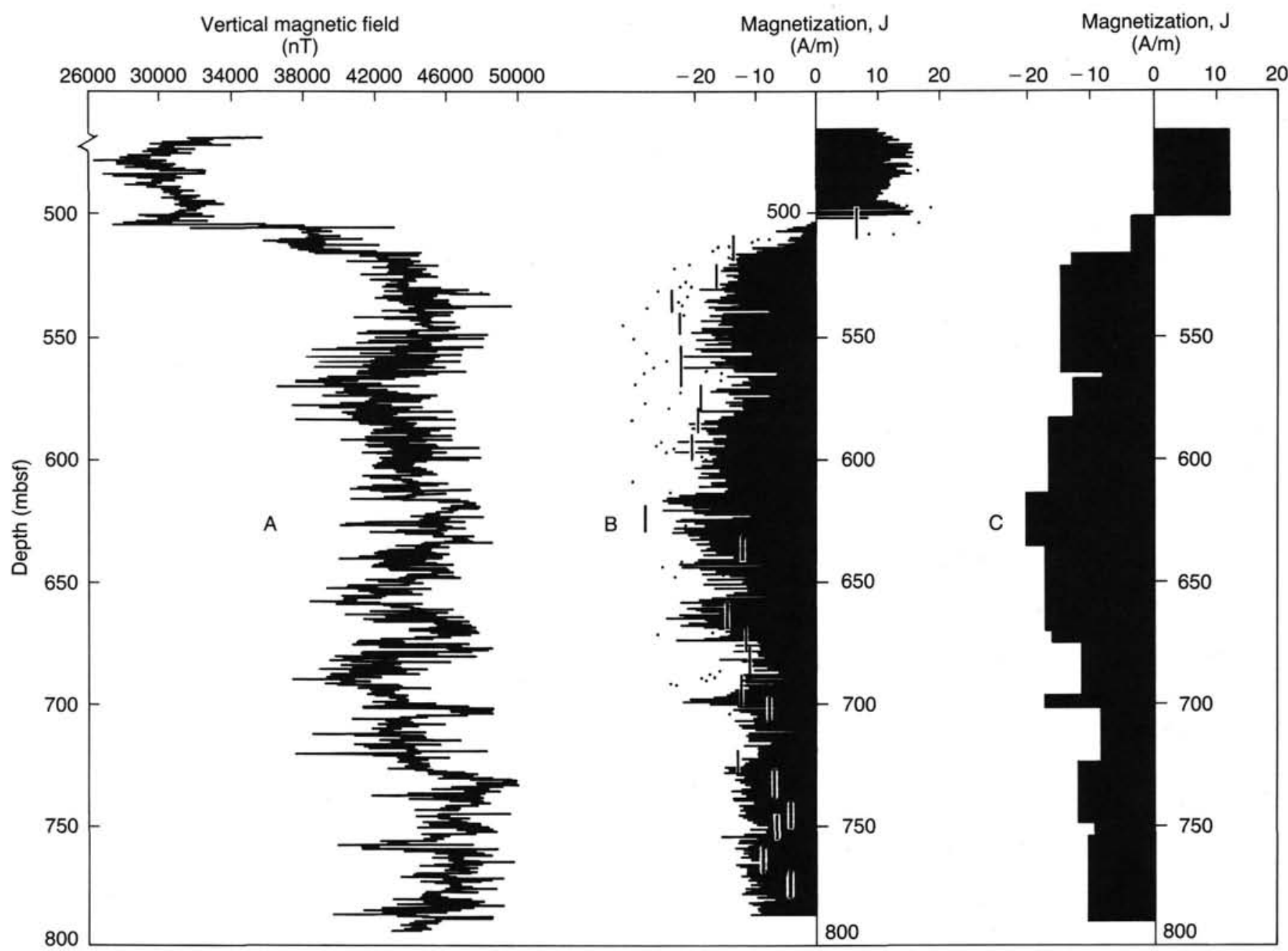

Figure 14. A. Magnetometer log of Hole 418A. B. Profile of total magnetization computed from magnetometer log by means of horizontal disk modeling technique. C. Simplified layer model formed by averaging values of total magnetization over qualitative magnetic units of column A, Figure 7 . Dots represent individual sample values (Levi, 1980), and bars represent averages of laboratory-measured NRM values of cores (Levi et al., 1980). 
trates the top of the dike zone (lithologic Subunit 14B), where the susceptibility rises abruptly to about $4 \times 10^{-3} \mathrm{cgs}$ units.

\section{CONCLUSIONS DRAWN FROM THE MAGNETOMETER AND SUSCEPTIBILITY LOGS}

Differences in the properties of the major lithologic units are reflected by both of the magnetic logs as well as by most of the other geophysical well logs (Broglia and Moos, this volume). Subunit 6A (504-514 mbsf), the breccia zone, is clearly defined by nearly all of the logs. The break between the pillow basalts of lithologic Subunit 6B and Unit 7 at $614 \mathrm{mbsf}$ is shown by both of the magnetic logs and also by the density and resistivity logs. Massive basalt Units 9 and 10 (676-686 mbsf) are represented on the magnetic logs and also on the gamma-ray, density, porosity, velocity, and resistivity logs (Broglia and Moos, this volume).

Because the lithologic boundaries are indicated by most of the geophysical logs, one would expect the lithologic units to correspond to discrete petrographic units as well. This is true for the breccia zone at 504-514 mbsf where the magnetic reversal occurs, for the massive basalt at $676-686 \mathrm{mbsf}$, and for the pillow and massive pillow basalts at 708-744 mbsf that appear to be a transition zone from pillow basalt to massive basalt. The boundary at 614 mbsf is not clearly understood; it may be the transition from pure pillow basalt to interlayering of pillows and massive basalt.

The low-susceptibility zone between 514 and $610 \mathrm{mbsf}$ is associated with high total magnetization. The Q-factor in this interval has been calculated as 80 , which agrees with the laboratory drill-core measurements made by Levi (1980).

The strong remanence can be explained by the petrophysical properties of the pillow basalts penetrated in this interval. The pillow basalt grain size is very small, indicating rapid cooling that caused the remanent magnetization to be very strong (Levi, 1980; Levi et al., 1980; Hamano et al., 1980).

From 610 to $725 \mathrm{mbsf}$ the susceptibility generally increases, reaching its highest levels between 645 and 725 mbsf. The susceptibility log shows considerable variability in this interval as does the magnetization profile, which decreases with depth but remains high on the average. The individual, thin high and low anomalies are probably caused by the intercalation of massive and pillow basalts. The response of the magnetic logs to the massive basalt between 676 and $686 \mathrm{mbsf}$ is quite clear, even though the Q-factor has a relatively low value of 11 from 610 to 725 mbsf.

From 725 to about 785 mbsf the magnetic logs and the magnetization profile show less scatter than higher up in the hole. Here the Q-factor is only 8, and the remanent magnetization is quite low, which is explained by slower cooling, as indicated by the larger grain size and greater homogeneity of this basalt unit (Levi, 1980).

Below 785 mbsf the magnetometer and susceptibility logs show the effects of the transition from massive basalt to the dike zone, which is characterized by decreasing susceptibility and decreasing remanent magnetization. The dike zone (which was not logged with the magnetometer probe) has high susceptibilities and, according to core measurements reported by Hamano et al. (1980), also has high magnetizations.

In overview, the magnetic logs reflect the petrophysical changes that occur below the breccia-reversal zone downward from the section dominated by pillow basalts, into the section of pillows intercalated with massive basalts, and finally into the massive basalts and the dike zone near the bottom of the logged interval (susceptibility log only). The relationship between the core-derived NRM values and the magnetization profile suggests that the boundary of the $M 0$ source body (Rabinowitz et al., 1980) may be less than $100 \mathrm{~m}$ away from the upper part of the hole and more than $100 \mathrm{~m}$ away from the lower part.

\section{THE 3-D MAGNETOMETER MEASUREMENTS}

As mentioned previously, 3-D measurements were obtained at 5-m intervals. The components of the Earth's magnetic field in the north-south, east-west, and vertical directions were calculated from measurements made with the Försterprobe three-axis magnetometer and the gyroscope-inclinometer positioning system. Because of the large diameter of the borehole (about $27 \mathrm{~cm}$ ) in comparison with the diameter of the probe $(9.2 \mathrm{~cm})$ and because the borehole was nearly vertical, the probe rotated continually about its axis and probably swung like a pendulum when it was held at fixed depths for 3-D readings. Furthermore, the probe moved up and down in response to the ship's heave, so it was never completely stationary when 3-D readings were made. These effects, which were not foreseen, compromised the usual evaluation procedure, and as a result, it was not possible to calculate the declination by taking an average of 10 measurements from one probe position as accurately as usual. (This problem has been solved by the use of a centralizer unit that was successfully tested on Leg 109.)

The anomaly vectors, calculated from the borehole 3-D measurements and then normalized by subtracting the Earth's regional field, are plotted in Figure 15 in the horizontal (A) and vertical (B) planes. In the vertical plane the vectors are plotted according to their true length (not projected to the N-S-vertical plane from the vertical plane in which they occur). The vectors' azimuthal direction can be determined from their projection on the horizontal plane in Figure 15A. The vectors are also plotted in Figures 16 and 17 in equal-angle projection on polar diagrams, on which the directions can be read more easily. Figures 18 and 19 show the downhole inclinations and declinations of the anomaly (and magnetization) vectors plotted versus depth. As described previously in "Data Reduction Methods," magnetization vectors can be calculated from the anomalies because the borehole transects the magnetic layer and the measurements are made inside the source body.

The most conspicuous feature of the anomaly-vector profile of Figure 15B is the change of sign at a depth of about $510 \mathrm{mbsf}$ from an upward to a downward direction, which is caused by a reversal in the Earth's paleomagnetic field. A more subtle change in the angle of dip of the vectors in Figure 15B (also seen in the inclination profile in Fig. 18) can be used to pick the boundaries of thick intervals (580-720 and 720-780 mbsf) with similar magnetic inclinations. These intervals correspond approximately to the section of the magnetometer log from 565 (lower boundary of section A) to 725 mbsf (lower boundary of section C) and below (Fig. 7).

The inclination values above about 510 mbsf scatter wildly, as do the magnetization vectors (Fig. 16), probably because of the proximity of the breccia zone and the reversal associated with it. Indeed, the geomagnetic field may have been changing rapidly just prior to the complete reversal. Below the breccia zone the inclinations of the magnetization vectors become more nearly constant at approximately $-25^{\circ}$ to a depth of about 590 mbsf, below which they increase to an average of about $-30^{\circ}$ to a depth of about 700 mbsf. The interval below 700 mbsf is characterized by magnetization vector inclinations averaging about $-40^{\circ}$. These values agree approximately with the laboratory core measurements of Levi (1980). It is interesting to note the systematic decrease in inclination with depth within each of these three intervals, a phenomenon that is more apparent in the borehole measurement data than in the laboratory data because of the relatively close spacing of the borehole measurements. The cause of these systematic inclination changes is not known.

The declination of anomaly vectors plotted in Figure 19 shows more scatter than the inclination data, due at least in part to error introduced by movement of the probe during data acquisi- 

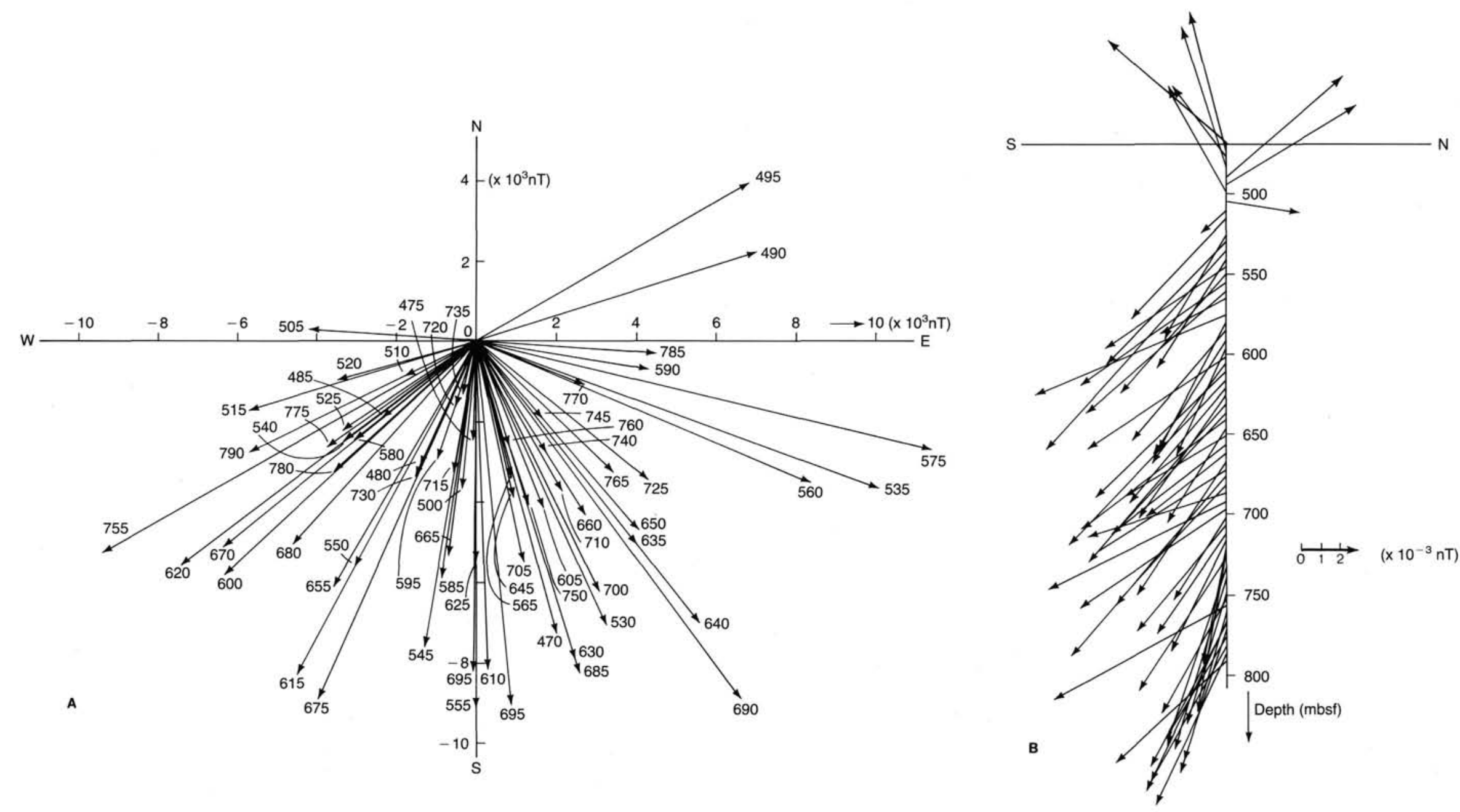

Figure 15. Anomaly vectors computed from 3-D magnetometer measurements in Hole 418A. A. Anomalies projected onto a horizontal plane, numbers indicate depths mbsf. B. Anomalies plotted in the vertical plane without foreshortening by projection. 


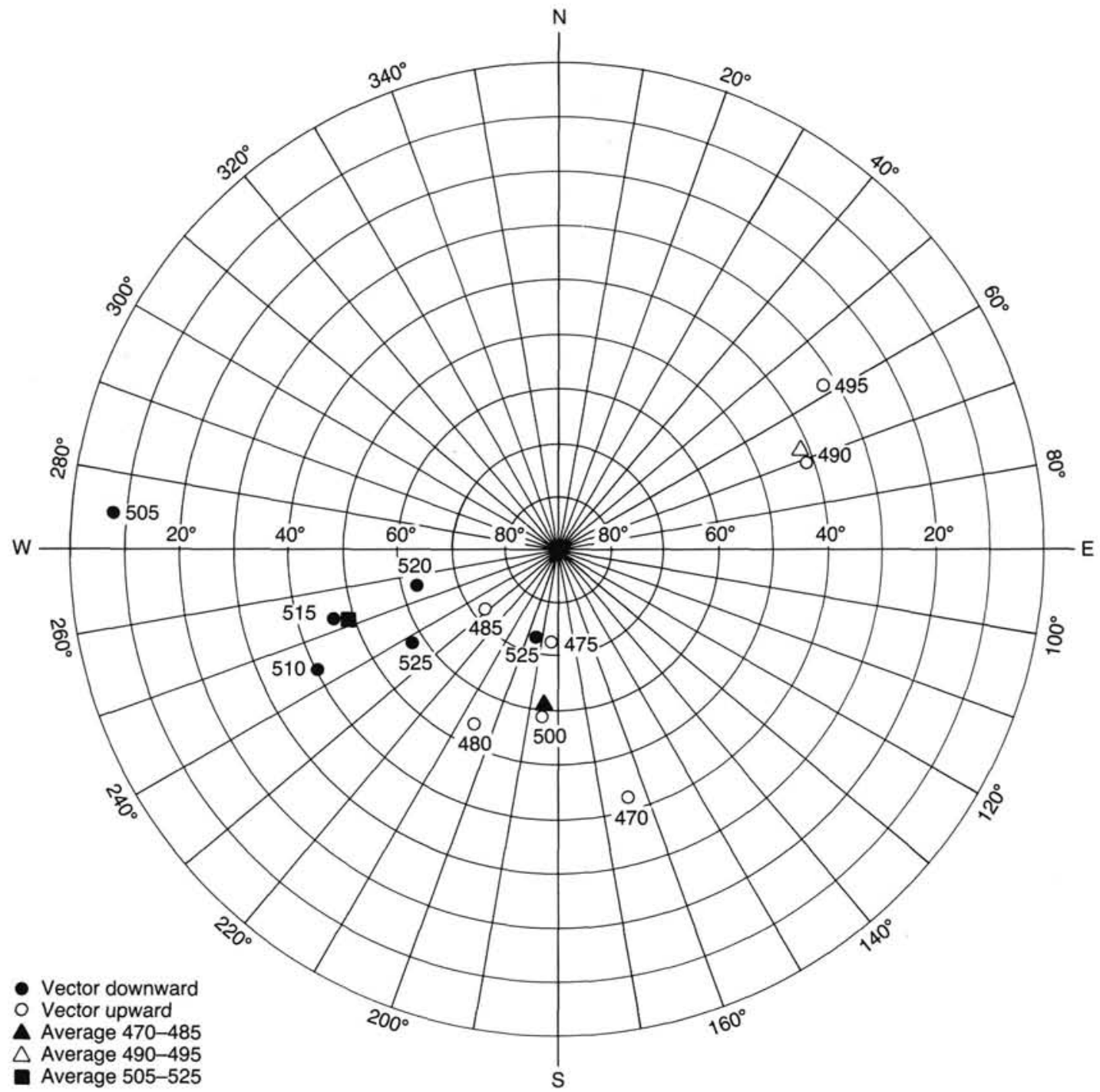

Figure 16. Anomaly vectors from the upper part of Hole 418A plotted in polar coordinates. Numbers indicate depths mbsf.

tion. Nevertheless, when these values are projected and plotted on a horizontal plane in Figure 17, they form a cluster of points.

This result together with the high average Q-factor of 36.6 encouraged us to attempt to relate the directions of the magnetization vectors to paleomagnetic age by computing pole positions for several depth intervals. Figures 20 and 21 show the Apparent Polar Wander Paths (APWP) for North America (Landolt-Börnstein, 1985) as solid black circles, along with the pole positions calculated from the 3-D borehole magnetometer data that we obtained in Hole 418A. Figure 20 shows the pole positions based on the average magnitudes of both the remanent and total magnetization vectors for the depth intervals indicated in the figure. As expected, the values derived from remanent magnetization agree quite closely with those based on total magnetization because of the large Q-factor. The pole positions computed for the depth intervals 510-565 and 580-715 mbsf and over the depth range from 530 to $790 \mathrm{mbsf}$ occur close to the track of the APWP for the magnetization vector data.

Figure 21 shows the APWP and the pole positions based on only the directions of the average magnetization vectors (unit vectors), which are usually considered more significant than vector magnitudes in paleomagnetic studies. In this case, the only declination-based pole positions that fit the trend of the APWP for the Hole 418A data are those for the interval 580-715 mbsf and over the 530 to 790 mbsf range.

The Fisher circles plotted on Figures 20 and 21 enclose the areas in which there is a $95 \%$ probability of the occurrence of the true average pole position determined from the borehole data. The computed pole positions for the interval 580-715 and over the range 530 to 790 mbsf are aligned with the APWP pole positions for the mid-Cretaceous, which is the age assigned to the crust at Site 418 from geologic age-dating information. The misfit of the pole positions based on the magnetization directions from the intervals $470-485$ and $510-565$ mbsf is attributed to their proximity to the reversal zone and the strong scattering of the borehole magnetic data associated with it.

The pole position based on borehole data from the interval 720-790 mbsf, which includes massive pillow basalt and massive basalt, is totally out of the APWP. Magnetic laboratory studies of the drill core from Hole 418A (Levi, 1980) also indicate that this interval is anomalous. Either of two mechanisms may be called on to explain this finding: (1) tectonic tilting or rotation or (2) variation of the Earth's magnetic field. Both possibilities are discussed in Part 2 of the Initial Reports of the Deep Sea 


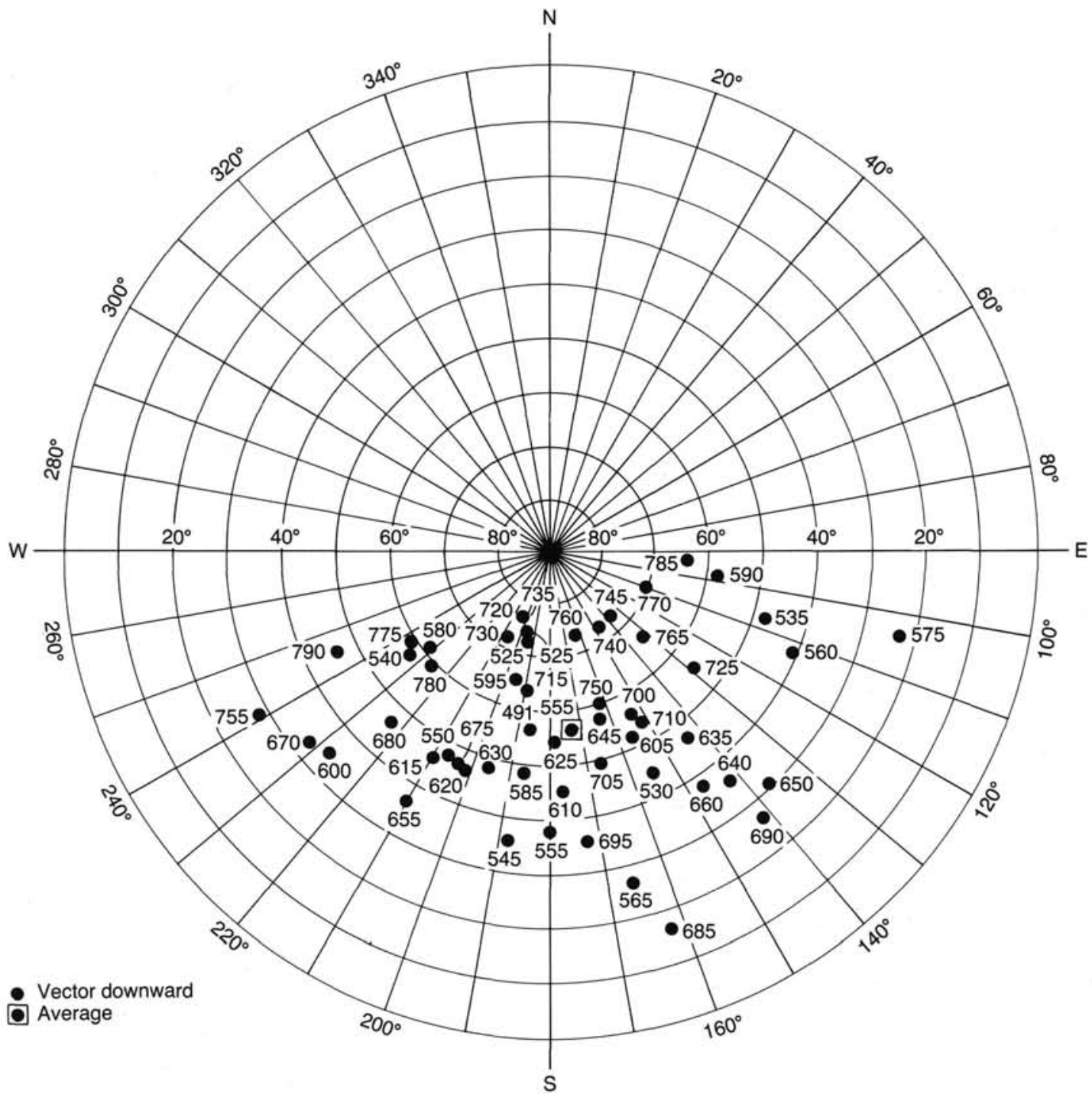

Figure 17. Anomaly vectors from the lower part of Hole 418A plotted in polar coordinates. Numbers indicate depths mbsf.

Drilling Project, Volume 51, 52, 53, with Levi (1980) arguing for field variations and Bleil and Smith (1980) and Kelts and Giovanoli (1980) for tectonic movement. The borehole magnetic measurements may shed some light on this question. The inclination data of Figure 18 show a gradual steepening below $680 \mathrm{mbsf}$ as the anomalous interval is approached. One would expect tectonic movement to cause a more abrupt change between the section affected by tectonic tilting and the undisturbed basalt. However, gravitational movement of the basalt flows while they were still mobile (prior to burial beneath younger flows) might explain the gradual change. On the other hand, variation of the Earth's magnetic field could easily explain the gradual change, and we favor this explanation because of its simplicity (see also Landolt-Börnstein, 1985).

\section{CONCLUSIONS}

Both magnetic logs, susceptibility and 3-D magnetometer, yielded interesting results regarding the in-situ magnetic properties of rocks penetrated by Hole 418A. The logs provided highresolution continuous profiles that made it possible to differentiate the section into several units with distinct and consistent magnetic properties. The greatest contrast in magnetic proper- ties is found between pillow basalts and massive basalts because of their different cooling rates, as evidenced by grain size differences, and because of chemical alteration related to fracture porosity (Broglia and Moos, this volume). The continuous nature of the magnetic profiles derived from the logs is their primary advantage over laboratory analyses of drill cores, which can only be made in the intervals where core is available. Furthermore, the gyroscope-oriented 3-D magnetometer readings can be interpreted to provide paleomagnetic declination data that cannot be obtained from core unless it is directionally oriented.

The combination of susceptibility and 3-D magnetometer measurements made it possible to compute remanent magnetization and paleomagnetic pole positions from in-situ borehole data for the first time in the history of ocean drilling research. Most of the pole positions calculated from borehole data followed the trend of the APWP reasonably well and placed the age of the oceanic basalts penetrated by Hole $418 \mathrm{~A}$ in the midCretaceous, in agreement with geologic information for the site. The pole position computed for the massive pillow and massive basalts near the bottom of the hole deviated from the APWP trend, probably because of variations in the Earth's magnetic field but possibly because of gravitational slumping or tectonic 


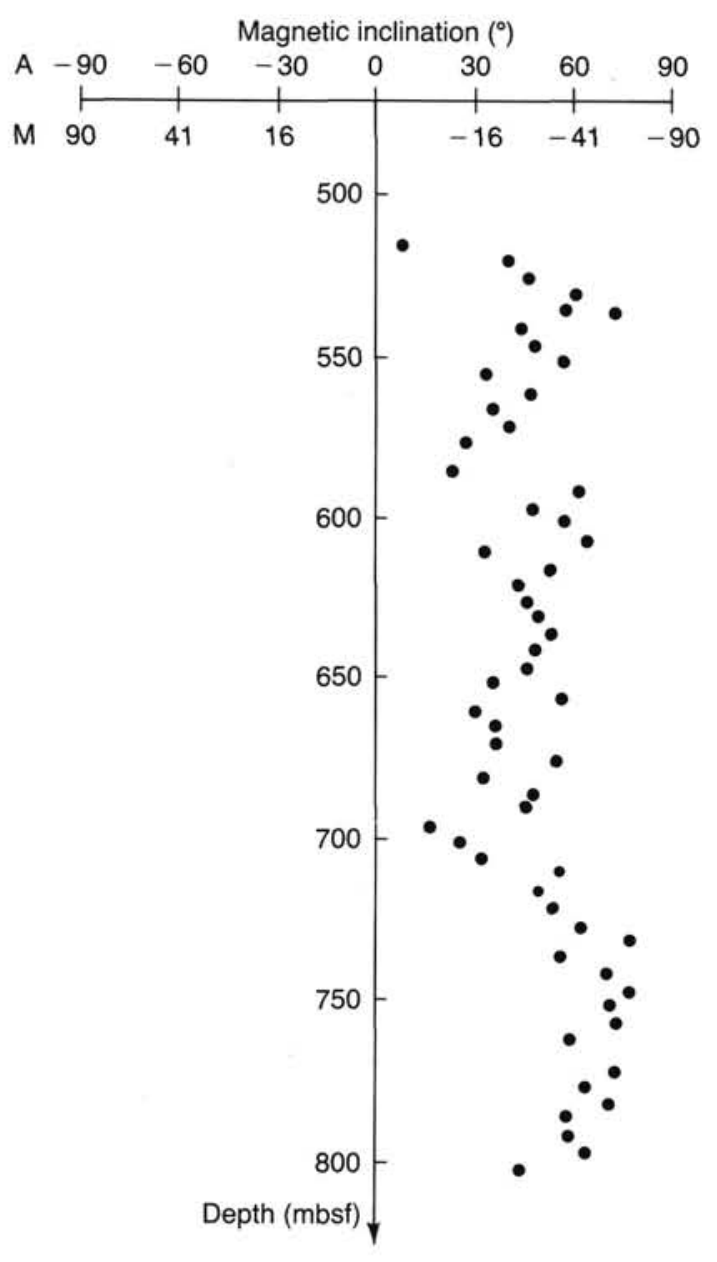

Figure 18. Downhole inclination of anomaly vectors (A) and magnetization vectors (M) plotted vs. depth in Hole 418A.

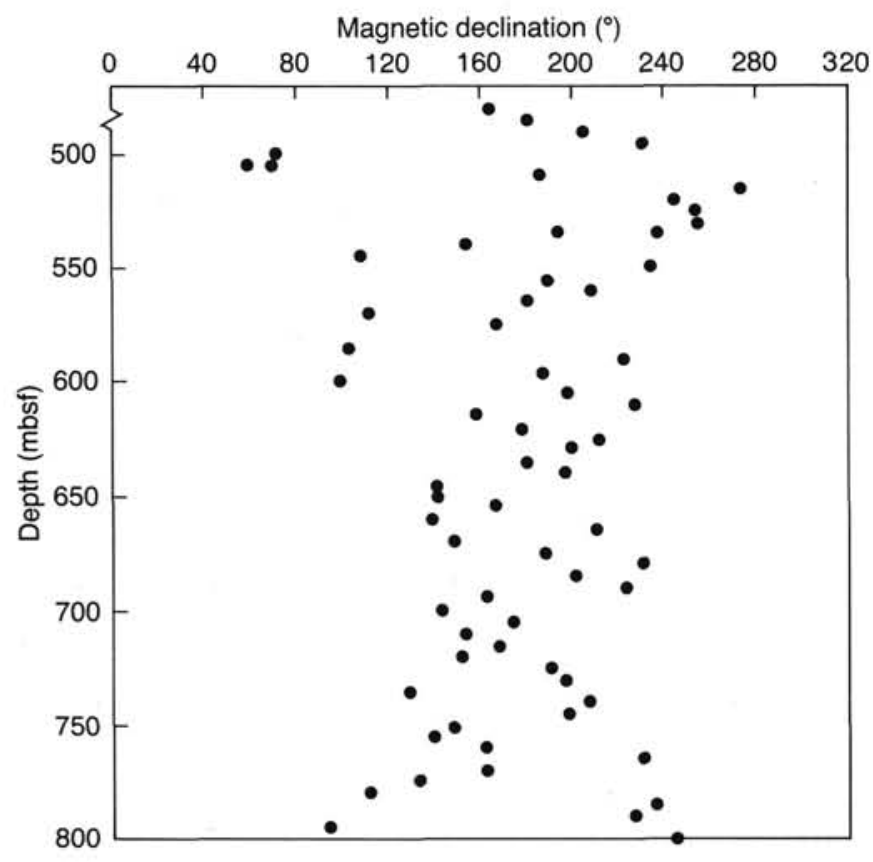

Figure 19. Downhole declination of anomaly vectors plotted vs. depth in Hole 418A.
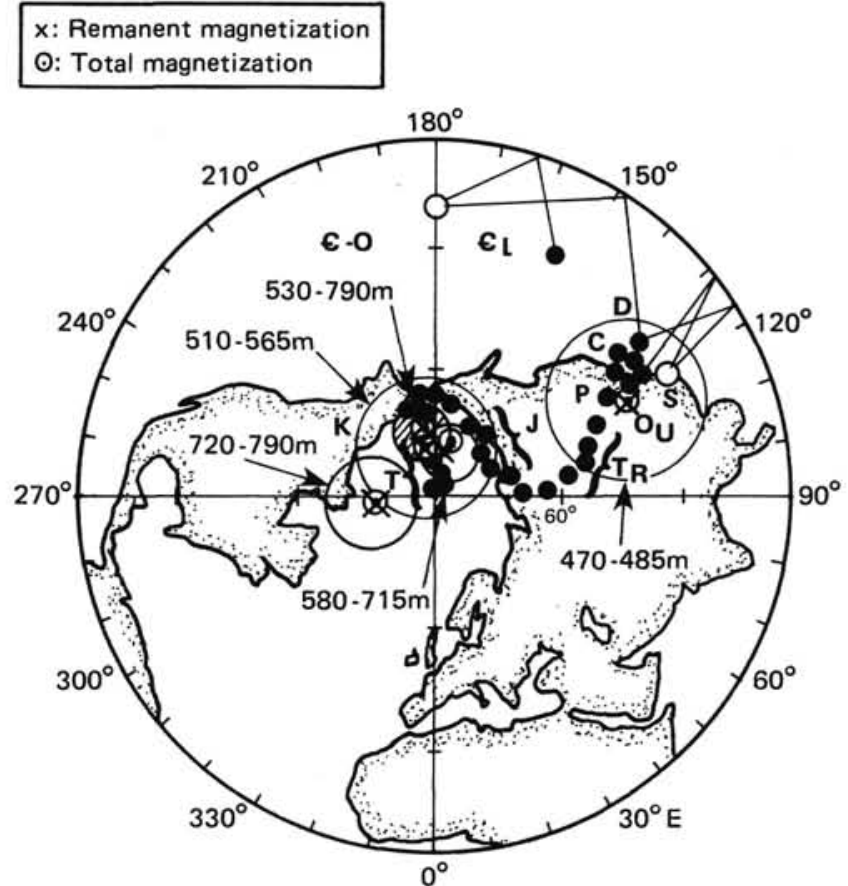

Figure 20. Apparent Polar Wander Paths (APWP, solid circles) and pole positions calculated from the magnetization vectors obtained from the 3-D magnetometer survey of Hole 418A for the depth intervals 470-485, $510-565,580-715,720-790$, and 530-790 mbsf. Fisher circles represent the probable variability of the mean pole positions at the $95 \%$ confidence level.

movement that occurred during or shortly after these basalts erupted. Laboratory magnetic measurements of core in this interval were also anomalous. In general, the borehole magnetic data compare quite well with the laboratory data.

The primary advantage of laboratory studies of the magnetic properties of core is the ability to remove "soft" magnetization by demagnetization techniques (e.g., alternating field and thermal demagnetization) and to remove secondary remanence of viscous or chemical origin (Levi, 1980). At the present time there are no techniques available for accomplishing this in the borehole. The precision and accuracy of laboratory magnetic measurements is also substantially higher than that of borehole measurements, which require strongly magnetic igneous or metamorphic rocks (such as oceanic basalts) to be effective.

Therefore, it can be concluded that both types of magnetic studies, borehole and laboratory, are complementary and are important in evaluating the magnetic properties of rocks drilled by the Ocean Drilling Program, and the Deep Sea Drilling Project.

\section{ACKNOWLEDGMENTS}

We acknowledge the assistance of Ewald Meyer of the Federal Institute for Geosciences and Natural Resources, Hannover, Federal Republic of Germany, in preparing and maintaining the 3-D magnetometer system for operation aboard the Resolution during Leg 102.

Prior to Leg 102, Ken Peters and Divyang Shah of LDGO wrote the computer programs for the Masscomp computer that were used to digitize, record, and playback the data from the USGS magnetic susceptibility probe. Dan Moos of LDGO modified the programs aboard the Resolution to meet unexpected requirements that arose during logging.

Michael Reitmeyer, ODP, provided valuable assistance in testing and troubleshooting problems with the ship's logging cable and cable head and in adapting them to the magnetic measurement probes. Glen Foss and Patrick Thompson, ODP, coordinated the magnetic logging with drill-pipe manipulations and probe maneuvering, which made it possible to log through the bridged zones in Hole 418A.

We are grateful to the Deutsche Forschungsgemeinschaft for providing travel funds for W. Bosum and E. Meyer for participation in Leg 102. 


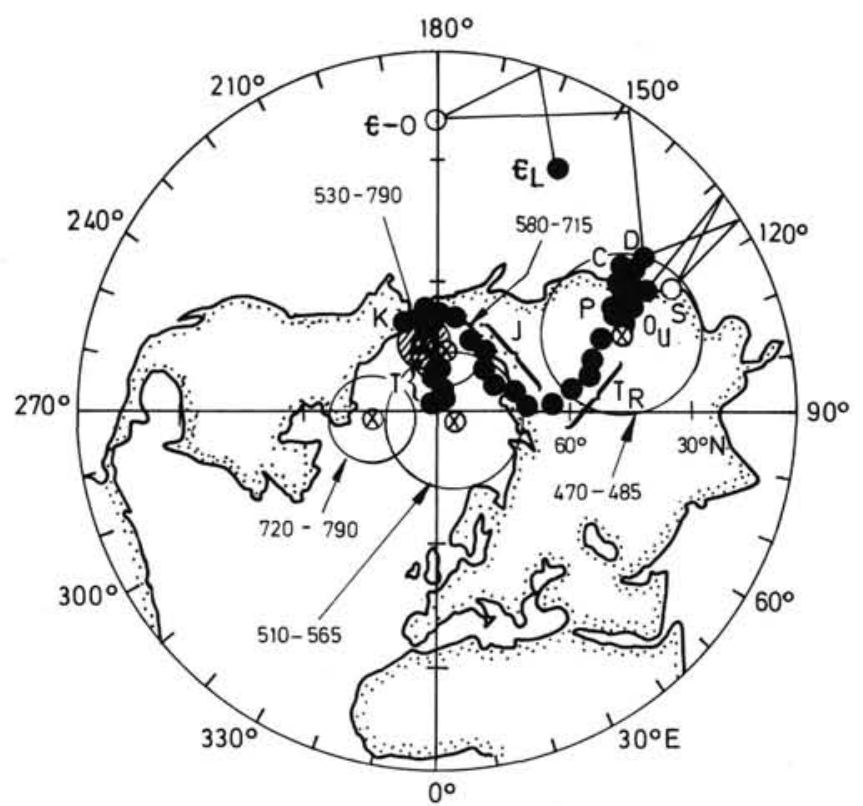

Figure 21. Apparent Polar Wander Paths (APWP, solid circles) and pole positions calculated from the magnetization directions (unit vectors) obtained from the 3-D magnetometer survey of Hole 418A for the depth intervals $470-485,510-565,580-715,720-790$, and 530-790 mbsf. Fisher circles (coded the same as for Figure 20) represent the probable variability of the mean pole positions at the $95 \%$ confidence level.

\section{REFERENCES}

Bleil, U., and Smith, B., 1980. Paleomagnetism of basalts, Leg 51. In Donnelly, T., Francheteau, J., Bryan, W., Robinson, P., Flower, M., Salisbury, M., et al., Init. Repts. DSDP, 51, 52, 53, Pt. 2: Washington (U.S. Govt. Printing Office), 1351-1361.

Bosum, W., 1985. Magnetische bohrlochmessungen in den Bohrungen Kirchzarten 1, 2 und 3 unter verwendung eines 3-D-bohrloch-magnetometers. Geol. Jahrb., Reihe E, 28:237-261.

Bosum, W., and Eberle, D., 1982. 3-D-Bohrlochmagnetometer-Entwicklung eines magnetischen bohrlochmessystems zur messung des magnetischen feldes in drei komponenten und bestimmung der magnetischen suszeptibilität. Entwicklung von auswertemethoden. Forschungsber. Bundesminist. Forsch. Technol. Entwick., NTS 3011:9.

Bosum, W., Eberle, D., and Rehli, H. J., in press. A gyro oriented 3-component borehole magnetometer for mineral prospecting and examples of application. Geophys. Prospect.

Donnelly, T., Francheteau, J., Bryan, W., Robinson, P., Flower, M., Salisbury, M., et al., 1980. Init. Repts. DSDP, 51, 52, 53: Washington (U.S. Govt. Printing Office).

Hamano, Y., Nishitani, I., and Kono, M., 1980. Magnetic properties of basalt samples from Deep Sea Drilling Project Holes 417D and 418A.
In Donnelly, T., Francheteau, J., Bryan, W., Robinson, P., Flower, M., Salisbury, M., et al., Init. Repts. DSDP, 51, 52, 53, Pt. 2: Washington (U.S. Govt. Printing Office), 1391-1405.

Kelts, K., and Giovanoli, G., 1980. Paleomagnetic directions from Lower Cretaceous interpillow limestones, Deep Sea Drilling Project Leg 51, Hole 417D, Bermuda Rise. In Donnelly, T., Francheteau, J., Bryan, W., Robinson, P., Flower, M., Salisbury, M., et al., Init. Repts. $D S D P, 51,52,53$, Pt. 2: Washington (U.S. Govt. Printing Office), 1429-1430.

Landolt-Börnstein, 1985. Numerical data and functional relationships in science and technology, new ser., group V. In Fuchs, K., and Soffel, H., Geophysics of the Solid Earth, the Moon and the Planets, subv. B of Geophysics and Space Research, v. 2: Heidelberg (SpringerVerlag).

Larson, R. L., and Hilde, T.W.C., 1975. A revised time scale of magnetic reversals for the Early Cretaceous and Late Jurassic. J. Geophys. Res., 80:2586-2594.

Levi, S., 1980. Paleomagnetism and some magnetic properties of basalts from the Bermuda Triangle. In Donnelly, T., Francheteau, J., Bryan, W., Robinson, P., Flower, M., Salisbury, M., et al., Init. Repts. $D S D P, 51,52,53$, Pt. 2: Washington (U.S. Govt. Printing Office), 1363-1378.

Levi, S., Bleil, U., Smith, B. M., and Rigotti, P. A., 1980. Compilation of paleomagnetic and rock magnetic results of basalt samples from Deep Sea Drilling Project Legs, 51, 52, and 53. In Donnelly, T., Francheteau, J., Bryan, W., Robinson P., Flower M., Salisbury, M., et al., Init. Repts. DSDP, 51, 52, 53, Pt. 2: Washington (U.S. Govt. Printing Office), 1337-1350.

Mooney, H. M., and Bleifuss, R., 1953. Magnetic susceptibility measurements in Minnesota, Part II: Analysis of field results. Geophysics, 18:383-393.

Ponomarev, V. N., and Nechoroshkov, V. L., 1983. First measurements of the magnetic field within the ocean crust: Deep Sea Drilling Project Legs 68 and 69. In Cann, J. R., Langseth, M. G., Honnorez, J., Von Herzen, R. P., White, S. M., et al., Init. Repts. DSDP, 69: Washington (U.S. Govt. Printing Office), 271-279.

1984. Downhole magnetic measurements in oceanic crustal Hole 395A on the Mid-Atlantic Ridge. In Hyndman, R. D., Salisbury, M. H., et al., Init. Repts. DSDP, 78B: Washington (U.S. Govt. Printing Office), 731-739.

Rabinowitz, P. D., Hoskins, H., and Asquith, S. M., 1980. Geophysical site summary results near Deep Sea Drilling Project Sites 417 and 418 in the Central Atlantic Ocean. In Donnelly, T., Francheteau, J., Bryan, W., Robinson, P., Flower, M., Salisbury, M., et al., Init. Repts. DSDP, 51, 52, 53, Pt. 2: Washington (U.S. Govt. Printing Office), 629-669.

Scott, J. H., 1984. Computer analysis of digital well logs. Geol. Surv. Circ. (U.S.), 879.

Scott, J. H., Seeley, R. L., and Barth, J. J., 1981. A magnetic susceptibility well-logging system for mineral exploration. Trans. SPWLA Annu. Logging Symp., 22:Pap. CC.

Snodgrass, J. J., 1976. Calibration models for geophysical borehole logging. Rep. Invest. U.S. Bur. Mines, RI 8148.

Date of initial receipt: 6 May 1987

Date of acceptance: 10 August 1987

Ms 102B-112 